\title{
Time course and task dependence of emotion effects in word processing
}

\author{
ANNEKathrin SCHacht ANd Werner Sommer \\ Humboldt University at Berlin, Berlin, Germany
}

\begin{abstract}
The emotional content of stimuli influences cognitive performance. In two experiments, we investigated the time course and mechanisms of emotional influences on visual word processing in various tasks by recording event-related brain potentials (ERPs). The stimuli were verbs of positive, negative, and neutral valence. In Experiment 1 , where lexical decisions had to be performed on single verbs, both positive and negative verbs were processed more quickly than neutral verbs and elicited a distinct ERP component, starting around $370 \mathrm{msec}$. In Experiment 2, the verbs were embedded in a semantic context provided by single nouns. Likewise, structural, lexical, and semantic decisions for positive verbs were accelerated, and an ERP effect with a scalp distribution comparable to that in Experiment 1 now started about $200 \mathrm{msec}$ earlier. These effects may signal an automatic allocation of attentional resources to emotionally arousing words, since they were not modulated by different task demands. In contrast, a later ERP effect of emotion was restricted to lexical and semantic decisions and, thus, appears to indicate more elaborated, task-dependent processing of emotional words.
\end{abstract}

A lot of reading is done for pleasure or excitement. Yet, although much is known about the reading process itself, only a little information is available about the impact of emotional content on reading. Thus, one would like to know when in time or, more precisely, at which stage of word processing emotion effects are functionally localized. The present study addressed this question in two experiments, employing the high temporal resolution of event-related brain potentials (ERPs).

Several studies have shown facilitated performance for emotional stimuli, as compared with neutral ones, ranging from simple detection tasks to memory retrieval (e.g., Cahill et al., 1998; Dahl, 2001; Dijksterhuis \& Aarts, 2003; Hamann, Ely, Grafton, \& Kilts, 1999). Many authors have explained such advantages of emotionally meaningful stimuli by their intrinsic relevance or salience (e.g., Lang, Bradley, \& Cuthbert, 1997), which attracts attention and prompts the allocation of further processing resources (e.g., Pessoa, Kastner, \& Ungerleider, 2002; Schupp, Junghöfer, Weike, \& Hamm, 2004; Vuilleumier, 2005). This assumption is in line with electrophysiological studies showing enhanced cortical responses to emotional pictures, as compared with neutral ones. Two emotion-related ERP components, distinguished by their time course and scalp topography, have been suggested to reflect distinct stages of emotion processing: the early posterior negativity (EPN; e.g., Junghöfer, Bradley, Elbert, \& Lang, 2001; Schupp, Hamm, \& Weike, 2003) and the late positive complex (LPC; e.g., Cuthbert, Schupp, Bradley, Birbaumer, \& Lang, 2000; Schupp et al., 2000). The EPN is a negativity at temporo-occipital electrode sites around 200 and $320 \mathrm{msec}$, which increases in amplitude to emotional pictures (e.g., Schupp et al., 2003). On the basis of its similarity to ERP components elicited by voluntary orientation of attention, the EPN is suggested to result from reflex-like visual attention, facilitating sensory encoding processes, and to reflect a transitory phase in which taskrelevant stimuli are selected for further, more elaborate processing (see Potts \& Tucker, 2001).

Elaborate processing of emotional stimuli is presumably reflected in the LPC. Augmented LPC amplitudes have been shown for emotionally arousing pictures of both positive and negative valence, as compared with neutral pictures (e.g., Cuthbert et al., 2000; Schupp et al., 2000; Schupp et al., 2003; Schupp et al., 2004). The LPC typically develops in the time range of the P300 component - that is, around $300 \mathrm{msec}$ - and lasts for several hundred milliseconds. Since the effect of positive emotional valence is similar, sometimes even larger as compared with negative valence, this effect is interpreted as being due to the emotional stimuli's increased motivational significance and arousal value (Kayser et al., 1997; Schupp et al., 2000). The P300 to nonemotional stimuli increases when the eliciting stimulus is attended (e.g., Johnson, 1988), infrequent, or task relevant (e.g., Picton \& Hillyard, 1988) and may, therefore, reflect processes of stimulus evaluation and memory updating (for reviews, see Bashore \& van der Molen, 1991; Polich, 2007). Given that processes similar to those in the P300 are reflected in the LPC, one may suggest that increased LPCs to emotional stimuli are due to continued perceptual analysis initiated by their higher intrinsic relevance.

Effects of emotion have been demonstrated in visual word processing, eliciting both EPN modulations (e.g., 
Herbert, Junghöfer, \& Kissler, 2008; Kissler, Herbert, Peyk, \& Junghöfer, 2007; Kissler, Herbert, Winkler, \& Junghöfer, 2009; see Kissler, Assadolahi, \& Herbert, 2006, for a review of heterogeneous evidence of early effects) and LPC modulations (e.g., Fischler \& Bradley, 2006; Herbert, Kissler, Junghöfer, Peyk, \& Rockstroh, 2006; Naumann, Bartussek, Diedrich, \& Laufer, 1992; Naumann, Maier, Diedrich, Becker, \& Bartussek, 1997). Since these effects were found even in silent reading tasks, which do not require any overt decisions on the words, the emotional valence of a word may be processed automatically. At variance with this automaticity hypothesis, there is some evidence that emotional LPC effects can be modulated by different task requirements, indicating that emotional effects in word processing increase as more semantic information has to be activated for successful task performance (e.g., Fischler \& Bradley, 2006; Naumann et al., 1992; Naumann et al., 1997). This is in line with task-dependent modulations of LPC amplitude in affective picture processing. For instance, Diedrich, Naumann, Maier, Becker, and Bartussek (1997) showed that LPC modulations in an emotion judgment task vanished when decisions about isolated visual features in the pictures were required. The extent of available attentional resources also appears to modulate the EPN in emotional picture processing (e.g., Schupp et al., 2007). In contrast, Kissler et al. (2009) found no modulation of the emotion effects in the EPN or LPC when they compared a silent reading task with a task in which words belonging to a particular word class were counted.

Such task-independent emotion effects in word processing might conform to the assumption that reading occurs automatically whenever a word is encountered (Kahneman \& Chajczyk, 1983; Stroop, 1935). However, reading may not be completely automatic, because outside of the emotion domain, there is strong evidence for task effects on the level at which a word is processed (e.g., McClelland \& Rumelhart, 1981; Seidenberg \& McClelland, 1989). For instance, the extent of semantic processing appears to modulate concreteness effects in both performance (Schwanenflugel, 1991) and ERPs (Kounios \& Holcomb, 1994; West \& Holcomb, 2000). Furthermore, Ziegler, Besson, Jacobs, Nazir, and Carr (1997) have shown that the type of task performed on stimuli alters lexicality effects in ERPs. These authors therefore suggested that multiple sources of linguistic information are used, depending on the task to be performed.

The suggestion of different linguistic sources leads directly to the question of whether there are distinguishable stages within the word recognition process at which those linguistic features are activated and, possibly, interact. Among word recognition models, there is a consensus that at least three different stages within the processing stream can be distinguished (e.g., Rastle, 2007). Reading begins with perceptual processes, defining the letters in the visual focus, followed by the translation of the letters' identities into a sequence of grapheme units and orthographic patterns, constituting particular words. This in turn results in the activation of lexical/phonological structures and their meanings.
An ongoing debate concerns the time course of the word recognition process. For instance, on the basis of ERP findings in repetition masking, Holcomb and Grainger $(2006,2007)$ postulated a sequence of distinguishable orthographic, lexical, and postlexical semantic-processing stages, taking place, in order, from 150 to $200 \mathrm{msec}$, from 250 to $400 \mathrm{msec}$, and after $400 \mathrm{msec}$ following word presentation onset. The suggested latency of the lexical stage is in line with most reports of the latency of the so-called lexicality effect, which appears after about $300 \mathrm{msec}$ (e.g., Braun et al., 2006; Chwilla, Brown, \& Hagoort, 1995; Hutzler et al., 2004). The lexicality effect consists of an enhanced negativity to orthographically and phonologically legal but nonexistent pseudowords or to illegal nonwords, when they have to be distinguished from existing words in lexical decision tasks. However, a number of recent studies have indicated that lexical operations may start very rapidly after stimulus onset. For instance, word frequency may modulate components of the ERP as early as $110 \mathrm{msec}$ after stimulus onset (e.g., Hauk, Davis, Ford, Pulvermüller, \& Marslen-Wilson, 2006; Hauk \& Pulvermüller, 2004; S. C. Sereno, Rayner, \& Posner, 1998). Finally, since the ERP effects of bigram and trigram frequencies can overlap in time with lexical effects, it has been proposed that the analysis of the orthographic structure does not have to be completed before the retrieval of semantic word content (see Hauk, Davis, et al., 2006; see also Pecher, Zeelenberg, \& Wagenmakers, 2005). The most prominent ERP component indicating postlexical semantic processing is the N400 (e.g., Kutas \& Van Petten, 1994), which has been suggested to reflect the activation of representations in semantic memory (Kutas \& Federmeier, 2000). Interestingly, N400 effects are larger when postlexical semantic processing is required (e.g., Kounios \& Holcomb, 1994; West \& Holcomb, 2000). However, there is also some evidence for semantic effects on ERP components prior to the N400. Differences between semantic word categories can appear already at less than $300 \mathrm{msec}$ after stimulus onset (e.g., Dehaene, 1995; Pulvermüller, Assadollahi, \& Elbert, 2001; Pulvermüller, Härle, \& Hummel, 2001), which is as early as the first differences induced by the lexical status (words vs. nonwords vs. pseudowords). Such data support models proposing that information about a word's meaning can be accessed nearly simultaneously with its orthographical/lexical information (e.g., Marslen-Wilson \& Tyler, 1980; see also Pulvermüller, Assadollahi, \& Elbert, 2001). Taken together, the ERP findings about the timeline of word comprehension seem to be most consistent with a time-variable sequence of cascaded (see McClelland \& Rumelhart, 1981) and possibly interactive (see Hauk, Davis, et al., 2006; Hauk, Patterson, et al., 2006) processes.

How and when do the emotional aspects of words impinge on these word recognition processes? Probably, due to the scarcity and diversity of the available evidence, there is as yet no implementation of emotion into models of word recognition. The suggestions extant in the literature are somewhat inconsistent. For instance, Keil, Ihssen, and Heim (2006) suggested that the processing stages that may be modulated by emotion include several possible 
“early" stages, such as sublexical analysis, lexical access, or subsequent processing. On the basis of the latency of their EPN emotion effects, Kissler and colleagues suggested the emotional content of a word to be activated not at a prelexical stage (Kissler et al., 2007), but "immediately after conceptual identification of the visual word form" (Kissler et al., 2009), which could be interpreted as a lexical or a postlexical locus. Most recently, Scott, O'Donnell, Leuthold, and Sereno (2009) reported an extremely early emotion effect on the visual P100 component combined with a significant interaction of emotion and word frequency in a lexical decision task, indicating both perceptual and lexical loci.

Taken together, it is obviously unclear whether the emotional content of written language impacts prelexical, lexi$\mathrm{cal}$, or postlexical stages of the reading processes. It was the general aim of the present study to contribute to the resolution of this problem: First, we assessed the time course of emotion effects during reading by means of recording ERPs, and second, we studied the interaction of emotion effects with several strictly defined task situations. In contrast to most of the previous studies of emotion effects on ERPs during word processing, we used verbs rather than nouns or adjectives. Verbs differ from other word classes by their very direct reference to actions and have been shown to elicit emotional effects in the attentional blink paradigm (Keil \& Ihssen, 2004; Keil et al., 2006).

Experiment 1 employed a lexical decision task (LDT) on emotionally positive, negative, and neutral single verbs. Experiment 2 addressed the influence of a minimal semantic context on the effects of emotional valence. A further aim of this experiment was to investigate the task dependence of these effects.

\section{EXPERIMENT 1}

In Experiment 1, we investigated the effects of emotional valence on word recognition by realizing a single-word LDT for correct German verbs and pseudowords. The aim of the present experiment was to elicit a speed advantage for emotional stimuli according to behavioral parameters, and to localize this effect within the information-processing system by means of recording ERP components.

\section{Method}

Participants. The data of 18 healthy participants (11 women), ranging in age from 18 to 31 years $(M=24.0$ years, $S D=3.6)$, were analyzed. Three of the participants were university employees; all the others were students. All the participants were right-handed apart from two left-handers (according to Oldfield, 1971). Participation was reimbursed with course credits or $€ 8 / \mathrm{h}$. All the participants were native German speakers with normal or corrected-to-normal vision and without any neurological or neuropsychological disorder, according to self-report.

Stimuli. The complete stimulus set consisted of 240 German verbs and 240 pseudowords. Correct words were verbs of positive (e.g., entspannen [to relax]), negative (e.g., vergiften [to poison]), or neutral (e.g., einlagern [to store]) valence taken from our own database on the basis of various unpublished rating and pilot studies by the present authors. This emotional categorization was verified postexperimentally. Pronounceable and orthographically legal pseudowords (e.g., besurgen) were constructed from correct verbs by sub- stituting one letter at a random position, excluding the first and last positions. All the verbs used were unambiguous candidates of their word class and were presented in their infinite form (lemmas). Verbs of different emotional valence were controlled for word frequency and number of orthographic neighbors (CELEX; Baayen, Piepenbrock, \& van Rijn, 1995), word length (letters and syllables), andaccording to postexperimental ratings — arousal and imageability. ${ }^{1}$

Procedure. The participants were seated in a dimly lit, soundattenuated chamber facing a computer monitor. The screen was situated at a distance of approximately $100 \mathrm{~cm}$ from the participants' eyes. All the stimuli were presented in white capital letters of the same font (Arial) on a dark gray background at the center of the screen. The vertical size of the letters was $8 \mathrm{~mm}$; the horizontal length varied between 35 and $65 \mathrm{~mm}$, depending on word length. A trial started with a fixation cross displayed for $500 \mathrm{msec}$, followed by the letter string, which disappeared with the response. After 2,700 msec (blank screen), the next trial started. The stimuli were delivered randomly in eight blocks of 60 items each. Between blocks, there was a short break. Stimulus presentation and response collection were controlled by the Experimental Run Time System software (BeriSoft, Germany).

The participants performed an LDT by responding with their left and right index fingers to correct words and pseudowords. The assignment of word type to responding finger was reversed for each participant after four blocks and was balanced in order across participants. Practice blocks consisting of 12 trials were given prior to the first and fifth blocks. The participants were instructed to avoid blinking while the stimuli were presented.

After the LDT, all correct verbs were presented again in a different random order. The participants had to judge the emotional valence of each verb on a 7-point rating scale by pressing buttons labeled from -3 to +3 on a standard PC keyboard. The participants were instructed to keep their fingers on the response keys (three fingers of each hand on keys labeled with \pm 1 to \pm 3 and one thumb on the space key labeled with 0 ).

Electroencephalogram data recording. The electroencephalogram (EEG) was recorded during the first experimental blocks (LDT) from 36 tin electrodes, referenced to the left mastoid. Most of these electrodes (Fp1, Fp2, Fz, F3, F4, F7, F8, FC5, FC6, FT9, $\mathrm{FT} 10, \mathrm{Cz}, \mathrm{C}^{\prime} 3, \mathrm{C}^{\prime} 4-4 \mathrm{~cm}$ to the left and right of $\mathrm{Cz}-\mathrm{T} 7, \mathrm{~T} 8, \mathrm{CP} 5$, CP6, Pz, P3, P4, P7, P8, P9, P10, PO9, PO10, O1, O2, and Iz) were placed in an electrode cap. Four external electrodes were used for the vertical and horizontal electrooculogram, and two for the left and right mastoid. Electrode impedance was kept below $5 \mathrm{k} \Omega$; ECI electrode gel (Expressive Constructs Inc., Worcester, MA) was used. Recording was done with a sampling rate of $250 \mathrm{~Hz}$. All channels were amplified with a bandpass of $0.032-70 \mathrm{~Hz}$. Offline, the continuous EEG record was segmented into epochs of 1,100 msec, starting $100 \mathrm{msec}$ prior to target onset and transformed to average reference. Corrections for artifacts due to blinks or vertical and horizontal eye movements were made using the method described by Gratton, Coles, and Donchin (1983). Epochs containing artifacts were discarded. ERPs were calculated for the edited set of raw data, considering only trials with correct answers. All ERP waveforms were referred to a $100-\mathrm{msec}$ prestimulus baseline.

Data analysis. From the 240 stimuli of the complete set, 40 were selected, for each emotion condition, that were unambiguously rated as belonging to a given emotional category and, in addition, controlled for the criteria described below. Emotional items were accepted if the rating values for valence across all participants ranged from -1 to -3 for negative verbs and from +1 to +3 for positive verbs. Items were accepted as neutral if ratings ranged between -1 and +1 . All the analyses reported below were based on this selected subset of target verbs, for which descriptive statistics are shown in Table 1. Across emotion categories, these verbs were comparable in mean word length with respect to number of letters and syllables, in mean word frequency, and orthographic neighborhood size [all $\left.F_{\mathrm{S}}(2,117)<1, p \mathrm{~s}>.4\right]$. According to postexperimental ratings, verbs did not differ in imageability $[F(2,117)=0.18, p>.98]$. Rat- 
Table 1

Descriptive Statistics (Mean Values With Standard Deviations) for

Control Variables and Rating Results for the Selected Subset of Word Material Used in Experiment 1

\begin{tabular}{|c|c|c|c|c|c|c|}
\hline & \multicolumn{2}{|c|}{$\begin{array}{c}\text { Positive } \\
\text { Verbs }\end{array}$} & \multicolumn{2}{|c|}{$\begin{array}{c}\text { Negative } \\
\text { Verbs }\end{array}$} & \multicolumn{2}{|c|}{$\begin{array}{c}\text { Neutral } \\
\text { Verbs }\end{array}$} \\
\hline & $M$ & $S D$ & $M$ & $S D$ & $M$ & $S D$ \\
\hline Emotional valence (range, -3 to +3 ) & 2.0 & 0.3 & -2.2 & 0.4 & 0.1 & 0.2 \\
\hline Arousal (range, 1-5) & 3.2 & 0.6 & 4.0 & 0.4 & 1.8 & 0.3 \\
\hline Imageability (range, $0-6$ ) & 3.5 & 1.3 & 3.6 & 1.4 & 3.5 & 1.2 \\
\hline Word length (number of letters) & 9.2 & 1.3 & 9.1 & 0.8 & 8.9 & 0.7 \\
\hline Word length (number of syllables) & 3.0 & 0.6 & 3.1 & 0.3 & 3.1 & 0.5 \\
\hline Word frequency $(1 / 1,000,000$, CELEX) & 50 & 78 & 51 & 73 & 50 & 59 \\
\hline Orthographic neighborhood size & 0.9 & 1.3 & 0.8 & 1.1 & 1.1 & 1.2 \\
\hline
\end{tabular}

ings of emotional valence revealed significant differences between all three conditions $[F(2,117)=1,960.6, p<.001$; all $t \mathrm{~s}(78)>32.0$, $p \mathrm{~s}<.001]$. Furthermore, statistical comparison of SAM ratings revealed increasing arousal values from neutral over positive to negative verbs $[t \mathrm{~s}(78)>6.5, p \mathrm{~s}<.001]$.

The percentage of wrong classifications and mean reaction times (RTs) for correct responses were analyzed by repeated measures ANOVAs involving the factor of emotional valence.

Segmentation of ERP amplitudes proceeded according to visual inspection of measures of global field power (GFP; Lehmann \& Skrandies, 1980) and global map dissimilarity (GMD; Brandeis, Naylor, Halliday, Callaway, \& Yano, 1992). GFP reflects the overall ERP activity across the scalp at any given moment. GMD reflects the dissimilarity between scalp topographies of adjacent time points and demarcates the borders between periods of relatively stable topographies indicating continued processing within similar brain areas.
These transition times were used as the limits of the time segments for which mean ERP amplitudes were calculated. GMD was calculated for maps of difference waves to, first, emotional minus neutral verbs, and, second, pseudowords minus all correct verbs (averaged over all emotion conditions). As is shown in Figure 1, the largest peaks in the GMD correspond well with changes in GFP. Accordingly, ERPs were quantified by calculating the mean amplitudes within the following time segments: $0-40,40-100,100-136,136-176,176-368$, 368-488, 488-684, 684-724, and 724-954 msec after target onset for assessing the effects of emotional valence, and $0-116,116-128$, $128-328,328-760$, and $760-1,000 \mathrm{msec}$ for the effects of lexicality.

Amplitude differences were assessed by two separate repeated measures ANOVAs: (1) for quantifying the effect of emotional valence (positive vs. negative vs. neutral) within the correct words, and (2) for detecting the lexicality effect (correct words averaged over all emotion conditions vs. pseudowords), disregarding emotional valence.

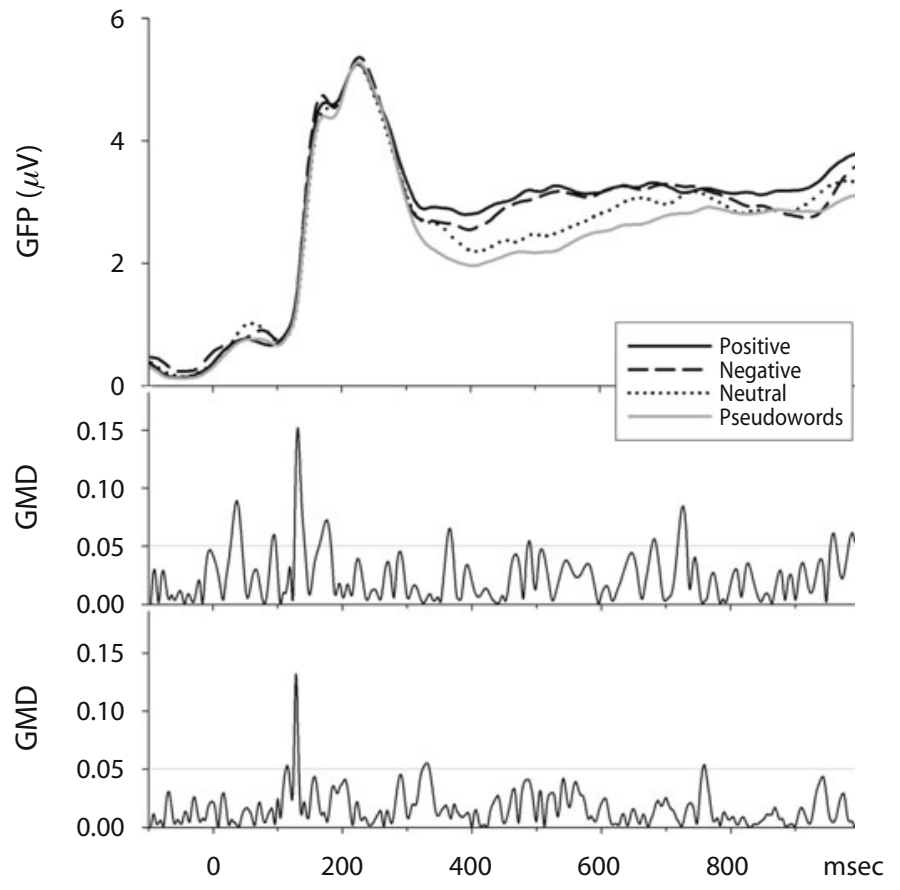

Figure 1. Effects of emotional valence and lexicality on electrophysiological parameters in Experiment 1. The upper graph shows global field power (GFP) across all participants, contrasted for emotionally positive, negative, and neutral words and for pseudowords. The lower graphs depict global map dissimilarity (GMD) of the difference between ERP distribution to emotional minus neutral (middle) and pseudowords minus correct words (bottom) across all participants. Horizontal gray lines mark the amplitude criteria for GMD peaks. 
By definition, the average reference sets the mean value of the ERP amplitude to zero across all electrodes within a given condition. Therefore, whenever all the electrodes are entered into the ANOVA, only effects in interaction with electrodes are meaningful. HuynhFeldt correction was applied to adjust the degrees of freedom of the $F$ ratios. All within-subjects repeated ANOVA measures will be reported with uncorrected degrees of freedom but corrected $p$ values. For pairwise comparisons, alpha levels were Bonferroni adjusted.

\section{Results}

Performance. The behavioral data are summarized in Table 2. An ANOVA revealed significant effects of emotional valence [for RTs, $F(2,34)=6.5, p<.01$; for error rates, $F(2,34)=4.8, p<.05]$. Pairwise comparisons revealed significantly shorter RTs for positive $[F(1,17)=$ $4.2, p<.05]$ and negative $[F(1,17)=3.5, p<.05]$ verbs, as compared with neutral verbs. Error rates were higher for positive than for neutral verbs $[F(1,17)=9.5, p<$ $.05]$. No other significant effects were obtained.

Event-related brain potentials. Figure 1 depicts GFP and GMD for emotionally positive, negative, and neutral correct verbs and pseudowords. ANOVAs over mean ERP amplitudes revealed a significant effect of emotional valence between 368 and $488 \mathrm{msec}[F(62,1054)=2.6, p<$ $.05, \varepsilon=.129]$, which consisted in significant differences between both emotionally positive $[F(31,527)=3.6, p<$ $.05, \varepsilon=.120]$ and negative $[F(31,527)=2.6, p<.05, \varepsilon=$ $.170]$ verbs, as compared with neutral verbs, but not between positive and negative verbs $[F(31,527)=1.3, p>.05, \varepsilon=$ $.292]$. As can be seen in Figure 2A, both conditions of emotion elicited larger negativities at parieto-occipital electrode sites than did neutral verbs. Therefore, we conducted an additional regional analysis by calculating the averaged activity of five occipito-temporal electrodes (PO9, PO10, O1, $\mathrm{O} 2$, and Iz). Repeated measures ANOVAs with factors of emotion (3) and electrode (5) confirmed the main effect of emotion obtained in the overall ANOVA $[F(8,136)=9.2$, $p<.001, \varepsilon=.385]$ and the differences between the neutral and both emotion conditions $\left[F_{\mathrm{s}}(4,68)>8.8, p \mathrm{~s}<.001\right.$, $\varepsilon s=.749$ and .457 , respectively] .

ERPs to correct verbs and pseudowords differed between 328 and $760 \mathrm{msec}[F \mathrm{~s}(31,527)=11.2, p<.001$, $\varepsilon=.157]$. As can be seen in Figure 2B, pseudowords elicited an enhanced negativity, as compared with correct words, irrespective of the word's specific emotional valence (cf. Figure 1), which was most pronounced at the vertex. This was confirmed by an additional ANOVA on mean amplitudes at the $\mathrm{Cz}$ electrode within this time segment $[F(1,17)=21.2, p<.001]$.

No significant effects of emotion or lexicality appeared within the other time segments. ${ }^{2}$

Table 2

Mean Reaction Times (RTs, in Milliseconds) and Error Rates in Percentages (With Standard Deviations) for Experiment 1

\begin{tabular}{lrrrrr}
\hline \multirow{2}{*}{$\begin{array}{c}\text { Emotional } \\
\text { Valence }\end{array}$} & \multicolumn{2}{c}{$\mathrm{RTs}$} & & \multicolumn{2}{c}{ Error Rates } \\
\cline { 2 - 3 } \cline { 5 - 6 } & $M$ & $S D$ & & $M$ & $S D$ \\
\hline Positive & 818.1 & 10.1 & & 2.5 & 0.4 \\
Negative & 824.3 & 9.2 & & 2.1 & 0.4 \\
Neutral & 842.6 & 10.8 & & 2.0 & 0.4 \\
Pseudowords & 897.9 & 3.7 & & 4.9 & 1.0 \\
\hline
\end{tabular}

\section{Discussion}

In line with other studies (Dahl, 2001; Pratto \& John, 1991; Scott et al., 2009; White, 1996), lexical decisions were faster to both emotionally positive and negative verbs than to neutral verbs. Also confirming previous reports (e.g., Braun et al., 2006; Chwilla et al., 1995), ERPs showed the expected effect of lexicality, consisting of a greater negativity for pseudowords than for correct words, starting around $320 \mathrm{msec}$. Effects of emotional valence began approximately $50 \mathrm{msec}$ after the onset of the lexicality effect and were similar for positive and negative verbs. These findings indicate, first, that emotional valence is activated immediately after lexical processing in the reading process. The present data therefore provide direct evidence for the suggestion of Kissler et al. (2007) that ERP enhancement to emotional words occurs not at a prelexical level; that is, it occurs "just after lexical access" (Kissler et al., 2007, p. 479). Second, that the ERP effects of positive and negative words are similar, relative to neutral words, supports a view of generalized arousal or attention effects. Interestingly, the emotion effect observed here shows a fronto-central positivity and occipitotemporal negativity. Although this emotion effect appeared at a latency that would be typical for the LPC or N400, its scalp distribution clearly differed from these components but was rather similar to the EPN effects recently reported in the literature (Herbert et al., 2008; Kissler et al., 2007; Kissler et al., 2009; Scott et al., 2009). This discrepancy may relate to differences in task settings or stimulus material. In contrast to the present experiment, the studies of Herbert et al. (2008) and Kissler et al. (2007; Kissler et al., 2009) used silent reading tasks and did not require overt decisions on the words. One might argue that such passive tasks enhance emotional processing. Thus, Schupp et al. (2007) recently showed that the EPN to affective pictures is smaller in counting tasks, as compared with passive viewing. However, in the study by Schupp et al. (2007), target pictures were defined by lines overlaying the actual pictures, possibly withdrawing attention from these pictures. Since lexical decisions in the present experiment required an explicit encoding of the presented verbs, withdrawal of attention from the words is an unlikely explanation for the relatively long latency of emotion effects. If anything, explicit processing, as required here, usually enhances experimental effects, relative to implicit processing. We are not aware of any examples in which a deeper level of processing attenuated the effect of an experimental variable. Therefore, we consider it implausible that the relatively late onset of initial emotion effects in words obtained in the present experiment might be due to requirements for explicit, deep processing of the stimuli.

Alternatively, the relative delay in the onset of emotion effects might relate to word class. Whereas the abovementioned studies with earlier emotion effects used nouns and adjectives, single verbs served as stimuli in the present experiment. At least for verbs and nouns, there are several hints toward differences in processing. For instance, nouns are acquired earlier during language development (e.g., Nelson, 1973) and are remembered more easily than 

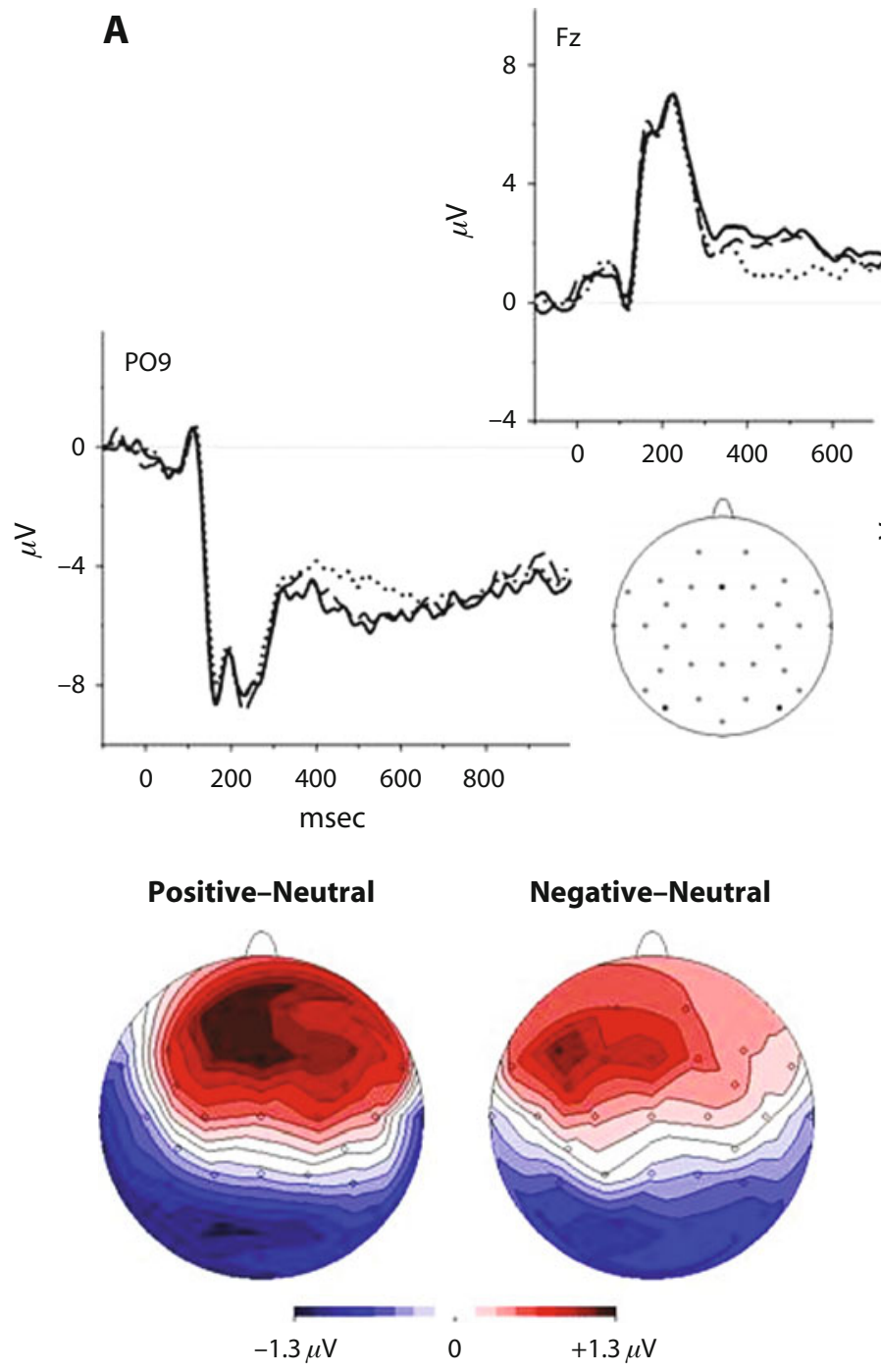

B

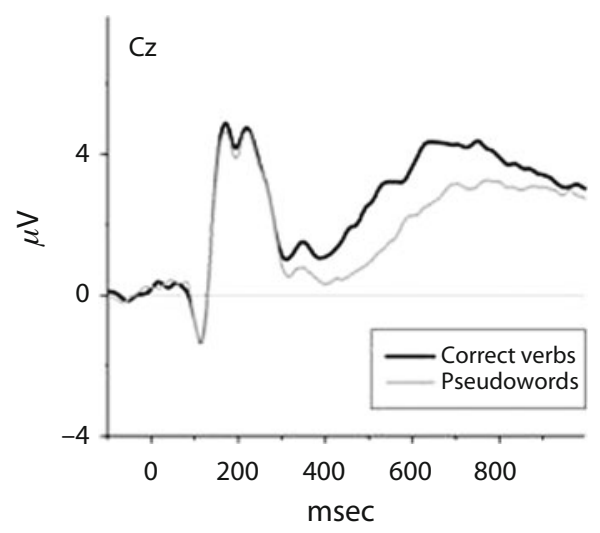

\section{Pseudowords-Correct Verbs}

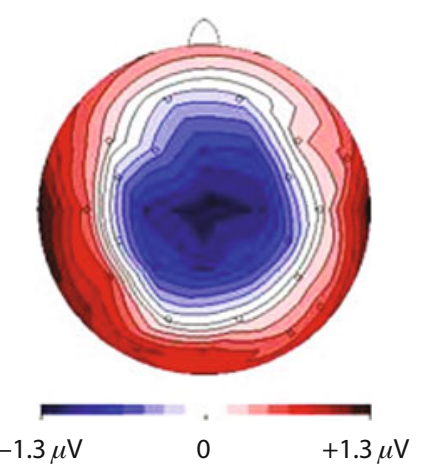

Figure 2. Effects of emotional valence and lexicality on ERPs. (A) Emotion effect. The upper panel depicts the grand mean ERP waveforms from frontal (Fz) and parietal (PO9 and PO10) electrodes, elicited by emotionally positive, negative, and neutral verbs. The lower panel shows the scalp distributions of the differences between positive and neutral verbs (left) and between negative and neutral verbs (middle) and, further, the distribution of ERPs to neutral verbs (right) within the 368- to 488-msec interval. (B) Lexicality effect. The left panel shows the grand mean ERP waveforms from the $\mathrm{Cz}$ electrode, elicited by pseudowords and correct verbs (averaged across all the emotion conditions). The right panel depicts the scalp distribution of the difference waves between pseudowords and correct words between 328 and 760 msec. 
verbs (e.g., Reynolds \& Flagg, 1976), possibly because of several syntactic and semantic differences (see Federmeier, Segal, Lombrozo, \& Kutas, 2000). Studies of visual word processing have shown such a noun advantage in a wide range of different tasks (e.g., Kauschke \& Stenneken, 2008; J. A. Sereno, 1999; Tyler, Russel, Fadili, \& Moss, 2001), which appears to interact with emotional valence, as has been shown by Dietrich et al. (2001) in a word recognition task. This idea is also supported by the most recent results of Scott et al. (2009), who found, apart from even earlier effects, an EPN for emotional nouns and adjectives at latencies similar to those in the silent reading paradigms (Kissler et al., 2007), but with an LDT similar to that in the present experiment. Further research will be needed to clarify whether such word class effects are related to differences in the time course of accessing the emotional meaning from written words of different classes. It also has to be noted that the verbs used here were quite long, as reflected in the RTs showing that successful discrimination between the experimental words and pseudowords took about $800 \mathrm{msec}$.

Another explanation for the relatively late effect of emotion might be that single verbs do not possess a consistent and stable emotional valence. Because much of the semantic meaning in linguistic information is conveyed by units that are larger than words (sentences or parts of sentences; see, e.g., Murphy, 1990), the emotional valence of single verbs might be unstable. This idea was supported by our data from postexperimental rating sessions, which, in many cases, revealed inconsistent valence ratings, necessitating a post hoc item selection. Consequently, the emotional valence of action words may depend on several additional aspects, such as agent or object information. For instance, the verb exploit might have a different emotional valence depending on whether it refers to an opportunity or to another person. Therefore, a main objective of Experiment 2 was to assess emotional valence effects when the verbs were embedded in a minimal semantic context.

\section{EXPERIMENT 2}

In order to provide a semantic context for the verbs of different emotional valence, they were combined with a preceding noun - for example, LOVER-KISS. The second objective of Experiment 2 was to examine whether the ef- fect of emotional valence found in Experiment 1 is influenced by different tasks performed on the words. In particular, we sought to investigate the effects of the emotional valence of words and their time course at different levels of processing. In analogy to Experiment 1, an LDT was performed on the target verbs. In addition, two different decision tasks were constructed. First, semantic decisions required judgments about whether the target verb was a meaningful follower of the preceding noun, and second, a shallow structural decision task was constructed requiring neither lexical nor semantic processing, since the participants had solely to decide whether all the letters within the string of the target verb were written in the same font or not. Whereas these three tasks focused on the implicit effects of emotional valence in word processing, a fourth task required explicit judgments of the emotional valence of the word pairs.

\section{Method}

Participants. All the participants $(N=24 ; 14$ women; age range, $18-32, M=23.5$ years, $S D=3.3$ ) were students and right-handed, apart from 3 who were left-handed. The participants were selected according to the same criteria and were reimbursed as in Experiment 1.

Stimuli. The stimuli consisted of three sets each of 120 meaningful German word pairs, consisting of a noun and an emotionally positive (e.g., LOVER-KISS), negative (e.g., MURDER-KILL), or neutral (e.g., MOTHER-CALL) verb, and 120 distractor word pairs. Nouns could present actor, object, or space information, according to the action or event described by the target verb. Verbs were presented in their infinite form (lemmas). All the words were written in capital letters of the same font (Arial). Emotional and neutral target verbs were selected on the basis of preexperimental valence ratings and were matched across emotion categories on word frequency, frequency of first syllable (CELEX; Baayen et al., 1995), and word length. According to these preexperimental ratings, emotional valence significantly increased from negative over neutral to positive target verbs $[t \mathrm{~s}(78)>19.7$, $p$ s $<.001]$. In separate rating studies,${ }^{3}$ the word pairs were judged for arousal, association strength between verbs and nouns, and imageability. SAM ratings for arousal did not differ between pairs with positive and negative verbs, but both conditions differed significantly from that with neutral targets $[t \mathrm{~s}(78)>2.5, p \mathrm{~s}<.05]$. Ratings of the noun-verb pairs did not differ in terms of imageability $[F(2,117)=$ $0.571, p=.57]$ but showed slight differences in association strength between nouns and target verbs. Here, emotionally positive verbs showed stronger associations to the preceding noun than did both neutral and negative verbs $[t \mathrm{~s}(78)>2.4, p \mathrm{~s}<.05]$. Importantly, statistical analysis did not reveal any differences between positive, negative, and neutral target verbs regarding such lexical variables as word frequency and word length $[F \mathrm{~s}(2,117)<2.3, p \mathrm{~s}>.1]$. Descriptive statistics are given in Table 3.

Table 3

Descriptive Statistics (Mean Values With Standard Deviations) for Control Variables and Rating Results for the Word Material of Experiment 2

\begin{tabular}{|c|c|c|c|c|c|c|}
\hline & \multicolumn{2}{|c|}{$\begin{array}{c}\text { Positive } \\
\text { Targets }\end{array}$} & \multicolumn{2}{|c|}{$\begin{array}{c}\text { Negative } \\
\text { Targets }\end{array}$} & \multicolumn{2}{|c|}{$\begin{array}{c}\text { Neutral } \\
\text { Targets }\end{array}$} \\
\hline & $M$ & $S D$ & $M$ & $S D$ & $M$ & $S D$ \\
\hline Emotional valence (range, -3 to +3 ) & 1.8 & 0.4 & -2.0 & 0.5 & 0.3 & 0.3 \\
\hline Arousal (range, $1-5$ ) & 3.7 & 1.2 & 3.8 & 1.2 & 2.4 & 1.1 \\
\hline Imageability (range, $0-6$ ) & 4.6 & 1.1 & 4.3 & 1.1 & 4.4 & 1.1 \\
\hline Association with prime (range, $0-4$ ) & 3.5 & 0.6 & 3.1 & 0.6 & 3.1 & 0.6 \\
\hline Word length (letters) & 8.8 & 1.7 & 9.4 & 1.6 & 9.2 & 1.6 \\
\hline Word length (syllables) & 2.9 & 0.7 & 3.1 & 0.6 & 3.1 & 0.6 \\
\hline Word frequency $(1 / 1,000,000)$ & 80 & 142 & 65 & 153 & 72 & 100 \\
\hline
\end{tabular}


To avoid any predictability of the target verbs based on the preceding nouns, each noun was combined with verbs of all three valences (e.g., MOUTH/LIPS/HAND-KISS/SCALD/GREASE), and each verb could be preceded by one of three nouns. ${ }^{4}$ In all, 40 sets of 9 such nounverb combinations were constructed. These 360 noun-verb pairs were uniquely assigned to one of three stimulus sets, so that each target verb was presented only once within a given stimulus set and with different nouns between sets. Each set was used for one of the three tasks, with set task assignment being counterbalanced across participants. The presentation of word pairs within the tasks was randomized.

Depending on the task, certain changes and additions had to be made in the materials. In the structural decision task, all the target verbs were meaningful followers of the noun, and distractor targets contained one italicized letter, which could appear equiprobably at a random position between the second and second-to-last positions of the verb (e.g., FATHER-PROTECT). The (pronounceable) pseudowords for the lexical decision task were derived from existing German verbs - not belonging to the correct item set—by exchanging one letter at a random position (e.g., SHIP-SAEL), excepting the initial and final positions. Distractor word pairs for the semantic decision task consisted of recombinations of nouns and verbs used for meaningful pairs, rendering their combination meaningless (e.g., BALLOONBRANCH). In all the tasks, the distractors were equally as frequent as the correct targets. The tasks were performed blockwise and were counterbalanced in order across participants.

Procedure. The trial scheme was identical for each of these three tasks. All the stimuli were presented at the center of a computer screen. Stimulus size was the same as that in Experiment 1. A trial started with a fixation cross, followed after an interval of $500 \mathrm{msec}$ by the noun, displayed for $500 \mathrm{msec}$, by another fixation cross $(1,000 \mathrm{msec})$, and by the verb, which disappeared with the response or, at the latest, after $1,500 \mathrm{msec}$. The participants responded to the verb by pressing one of two keys as quickly and accurately as possible. After 1,500 msec (blank screen), the next trial started.

In the final rating task, all the word pairs $(n=360)$ were presented again in a random order. In contrast to the other tasks, both words of a pair were presented simultaneously side by side until the keypress, followed by a blank screen of $1,500 \mathrm{msec}$. To avoid excessive EEG artifacts, a 5-point rating scale from - 2 (very unpleasant) to +2 (very pleasant) was used. All other task requirements followed the same procedure as that for the rating task in Experiment 1.

EEG recording. EEG recording was performed during the whole experiment, including the rating task, and followed the same procedure as that in Experiment 1.

Data analysis. Because stimulus presentation and response requirements in the rating task differed from those in the three preceding tasks, both the EEG and the behavioral data collected during the rating condition were analyzed separately. Behavioral responses were analyzed by repeated measures ANOVAs, involving the factors of emotional valence (positive, negative, or neutral) and task (structural, lexical, or semantic).

ERPs to the correct target verbs were derived for each task, condition, and electrode for trials with correct responses. In analogy to Experiment 1, ERP segmentation proceeded according to visual inspection of GFP and GMD measures (see Figure 3).

GFP indicated valence effects between about 100 and $700 \mathrm{msec}$ after verb onset. Within this interval with possible valence effects, GMD to maps of difference waves between emotional and neutral target verbs identified five microstates with transitions at about 88, 180, 292, 404, 448, 560, 672, and $956 \mathrm{msec}$ (Figure 3, left panel). These transition time points were used as limits of the time segments, for which mean ERP amplitudes were calculated relative to a $100-\mathrm{msec}$ pretarget baseline. Amplitude differences within these time segments were assessed by a repeated measures ANOVA (ANOVA 1), involving factors of emotional valence (positive, negative, or neutral) and task (structural, lexical, or semantic). As is depicted in the middle panel of Figure 3, GFP and GMD in-
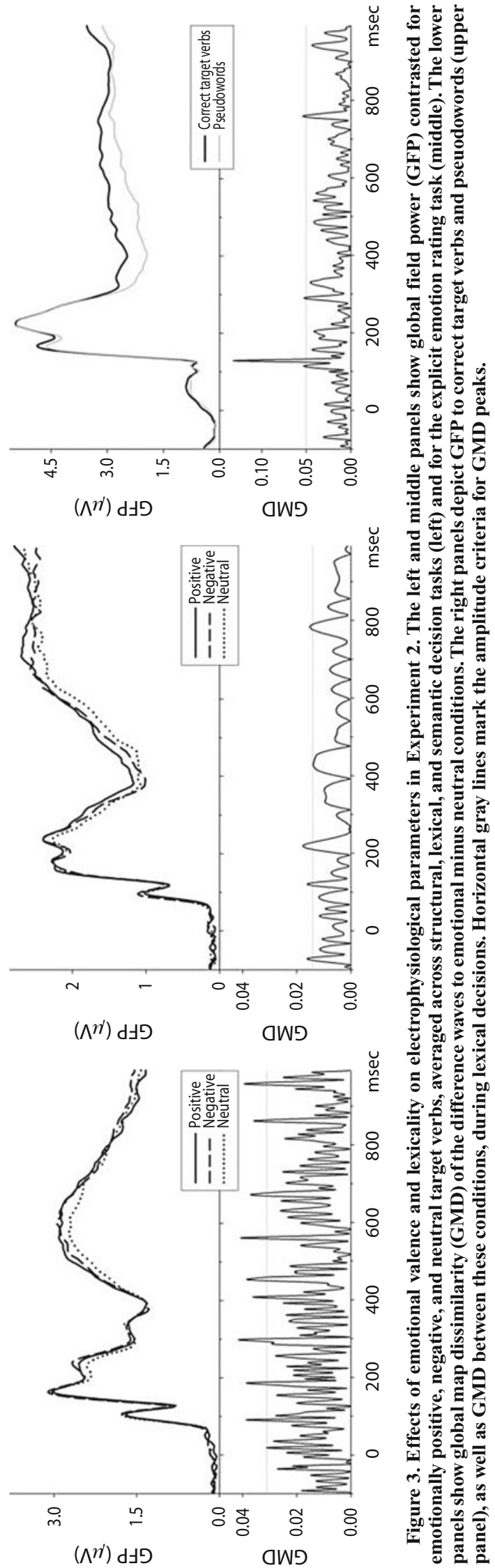
dicated different microstates in the rating task data, as compared with the three other tasks. Following visual inspection, mean ERP amplitudes were calculated in the following time segments: 0-120, 120-220, 220-432, 432-784, and 784-1,000 msec. Mean amplitudes in these time segments were assessed by a repeated measures ANOVA (ANOVA 2), involving the factor of emotional valence (positive, negative, or neutral). On the basis of the same procedure, by using GFP and GMD, the lexicality effect was analyzed as the difference between pseudowords and correct words restricted to the lexical decision task within the following time segments: $0-112$, 112-128, 128-276, 276-768, and 768-1,000 msec (ANOVA 3; see Figure 3, right panel).

In analogy to Experiment 1, additional regional analyses were calculated for ERP effects obtained in the overall ANOVAs described above.

In order to provide an estimate of the generator sources of the emotion effect, dipole source models were determined using the Brain Electromagnetic Source Analysis program (Scherg \& Berg, 2000) with a four-shell spherical head model (i.e., brain, bone, cerebrospinal fluid, and scalp). A source model is derived by fitting the source model iteratively to the data until a minimum in residual variance is reached.

\section{Results}

Performance. RTs to the target verbs were influenced by their emotional valence $[F(2,46)=61.7, p<.001]$. Positive emotional valence shortened RTs, as compared with both neutral $[F(1,23)=109.8, p<.001]$ and negative $[F(1,23)=72.4, p<.001]$ verbs (see Table 4 ), whereas RTs to neutral and negative verbs did not differ from each other. The size of the valence effect depended on the task $[F(4,92)=6.1, p<.001]$; for positive verbs, relative to neutral verbs, this effect increased from the structural over the lexical to the semantic task $\left[M_{\text {diff }}\right.$ (neutral positive) $=31,65$, and $74 \mathrm{msec}$, respectively]; for negative versus neutral words, the difference was small and not systematically modulated by the task.

ANOVAs for error rates revealed main effects for task $[F(2,46)=15.1, p<.001]$ and emotional valence $[F(2,46)=23.9, p<.001]$ and, furthermore, a significant interaction of task and emotional valence $[F(4,92)=10.3$, $p<.001]$. Error rates increased from the structural over the lexical to the semantic task. However, independently of the specific task, positive verbs were more often responded to correctly than were both negative and neutral verbs, whereas the latter did not differ significantly (see Table 4).

Confirming the preexperimental classifications, postexperimental ratings of emotional valence were higher for pairs with positive target words $(M=1.0, S D=0.8)$ and lower for pairs with negative target verbs $(M=-1.3$, $S D=0.8)$, as compared with neutral targets $(M=0.2$,
$S D=0.9)$. Both positive and negative pairs differed significantly from neutral pairs $(t \mathrm{~s}>27.0, p \mathrm{~s}<.001)$. Descriptive statistics for the rating values obtained in this emotional rating task are summarized in Table 3.

Effects of emotional valence in ERPs. ANOVA 1 revealed a first valence effect in the mean ERP amplitudes for the time segment between 180 and $292 \mathrm{msec}[F(62,1426)=$ $2.0, p<.05, \varepsilon=.177]$. This valence effect did not interact with task $(F<1)$ and consisted of amplitude differences between the neutral valence condition and both the positive $[F(31,713)=2.3, p<.05, \varepsilon=.216]$ and the negative $[F(31,713)=3.0, p<.01, \varepsilon=.231]$ valence conditions (see the upper panel of Figure 4A). The middle panel of Figure 4A depicts the maps of difference waves for the valence effects (positive minus neutral and negative minus neutral, respectively), and further, the scalp distribution of ERPs to neutral verbs. For both negative and positive target verbs, the ERP effects basically consisted of enhanced frontal positivities and parieto-occipital negativities. Regional analyses on activity of five occipito-temporal electrodes (PO9, PO10, O1, O2, and Iz) confirmed the main effect of emotion $[F(8,184)=6.8, p<.001, \varepsilon=.609]$ and revealed significant differences between ERPs to emotionally positive and neutral verbs $[F(4,92)=8.0, p<.01, \varepsilon=$ $.544]$, as well as between negative and neutral target verbs $[F(4,92)=9.4, p<.001, \varepsilon=.727]$. The scalp distribution of this emotion effect is typical for inferotemporal brain sources. To verify this impression, we modeled the neural sources of the early emotion effect between 180 and $292 \mathrm{msec}$. Grand average ERPs were calculated for neutral verbs and both kinds of emotional verbs (positive and negative). Spatial principal component analysis (PCA) for both conditions indicated that two principal components explained $99.6 \%$ of the variance within this time segment (PC1, 97.3\%; PC2, 2.3\%). In both conditions, a symmetric dipole pair accounted for $94 \%$ of the variance. Figure 4A (bottom panel) depicts the dipole pair fitted for the neutral condition; it was located in the fusiform gyrus (Talairach \& Tournoux, 1988; coordinates: $x= \pm 45 \mathrm{~mm}, y=-54 \mathrm{~mm}$, $z=-14 \mathrm{~mm}$; residual variance $=4.0 \%$ ). The dipole pair fitted for the emotional condition was located in exactly the same cortical brain area $(x= \pm 45 \mathrm{~mm}, y=-52 \mathrm{~mm}$, $z=-14 \mathrm{~mm}$ ).

In the following segments between 292 and $560 \mathrm{msec}$, there was no effect of emotional valence $[F \mathrm{~s}(62,1426)<$ $1.8]$ and no interaction of emotional valence and task $[F \mathrm{~s}(124,2852)<1.3]$. However, a main effect of emotional valence reappeared in the next, $560-672 \mathrm{msec}$ seg-

Table 4

Mean Reaction Times (RTs, in Milliseconds) and Error Rates in Percentages (With Standard Deviations) for Experiment 2

\begin{tabular}{|c|c|c|c|c|c|c|c|c|c|c|c|c|c|c|c|c|}
\hline \multirow[b]{4}{*}{ Task } & \multirow{2}{*}{\multicolumn{6}{|c|}{ RT }} & \multirow{2}{*}{\multicolumn{6}{|c|}{ Error Rate }} & \multicolumn{4}{|c|}{ Grand Means } \\
\hline & & & & & & & & & & & & & & & & \\
\hline & \multicolumn{2}{|c|}{ Positive } & \multicolumn{2}{|c|}{ Negative } & \multicolumn{2}{|c|}{ Neutral } & \multicolumn{2}{|c|}{ Positive } & \multicolumn{2}{|c|}{ Negative } & \multicolumn{2}{|c|}{ Neutral } & \multicolumn{2}{|c|}{ RT } & \multicolumn{2}{|c|}{ Rate } \\
\hline & $M$ & $S D$ & $M$ & $S D$ & $M$ & $S D$ & $M$ & $S D$ & $M$ & $S D$ & $M$ & $S D$ & $M$ & $S D$ & $M$ & $S D$ \\
\hline Structural decisions & 811.4 & 33.9 & 833.0 & 35.6 & 843.0 & 36.0 & 2.0 & 0.5 & 1.7 & 0.4 & 2.0 & 0.5 & 845.3 & 32.5 & 1.9 & 0.3 \\
\hline Lexical decisions & 769.0 & 30.3 & 821.2 & 32.9 & 832.3 & 30.3 & 2.3 & 0.5 & 5.3 & 0.9 & 4.7 & 0.8 & 804.2 & 30.0 & 4.1 & 0.5 \\
\hline Semantic decisions & 804.1 & 19.3 & 875.3 & 26.0 & 882.2 & 21.7 & 7.4 & 1.2 & 15.3 & 1.9 & 15.3 & 2.0 & 859.8 & 21.1 & 12.7 & 1.5 \\
\hline Grand means & 792.7 & 24.3 & 839.8 & 23.5 & 852.5 & 26.5 & 3.4 & 0.5 & 7.4 & 0.8 & 7.3 & 0.6 & & & & \\
\hline
\end{tabular}



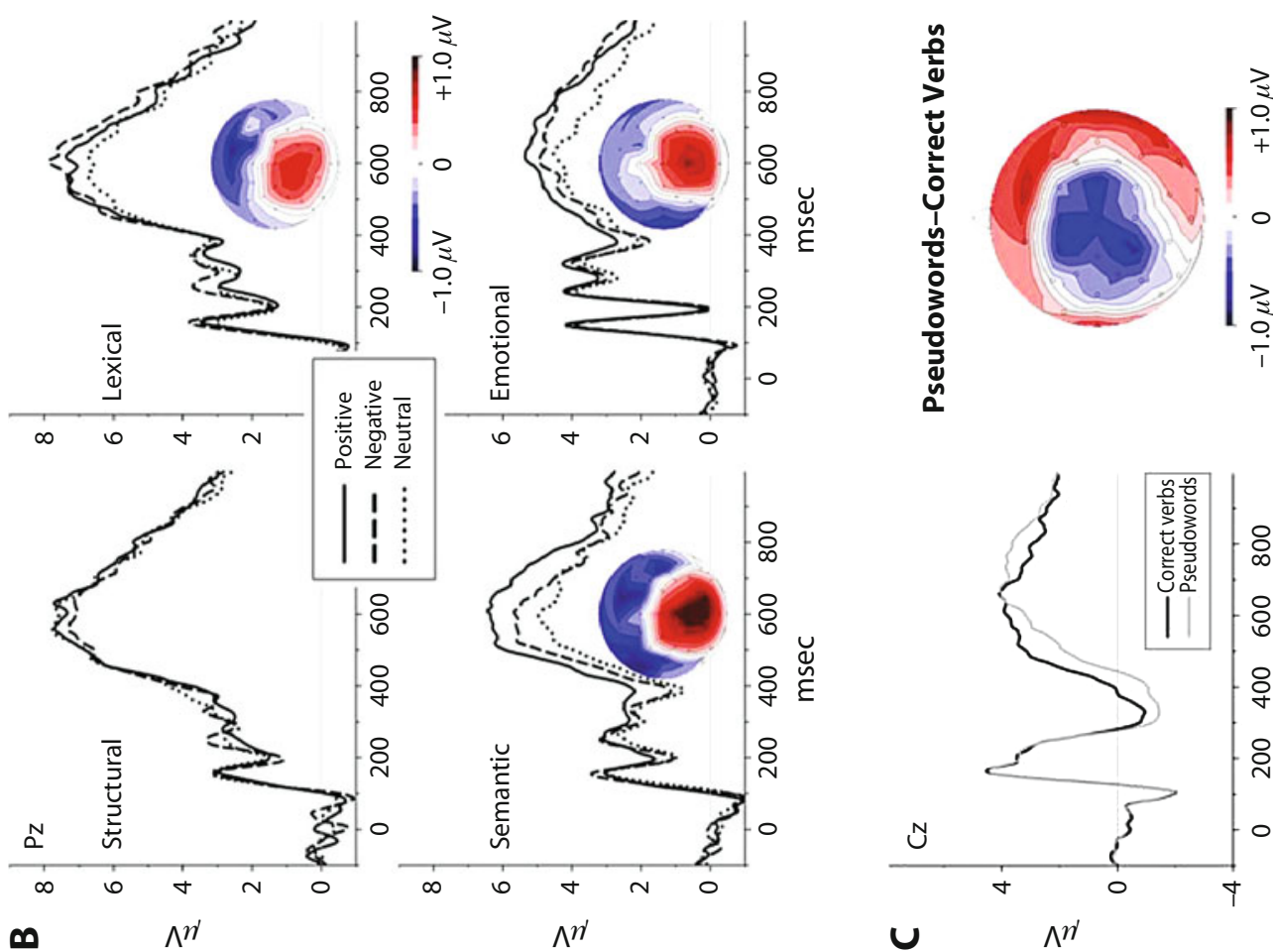

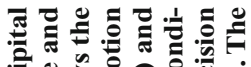

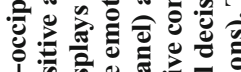

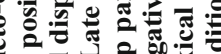

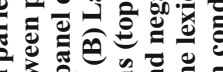

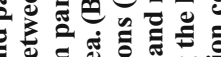

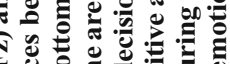

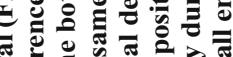

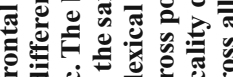

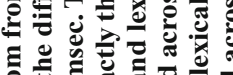

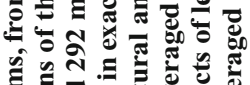

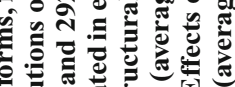

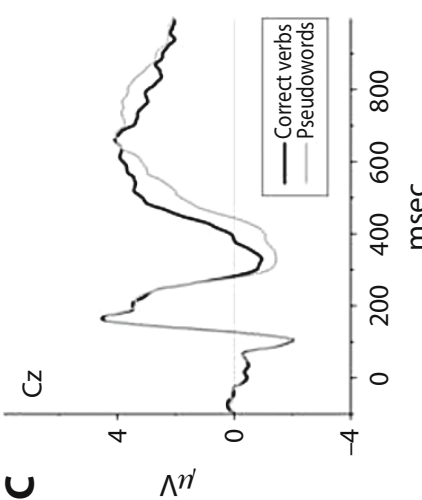
을 응 政

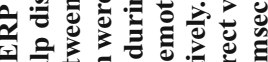

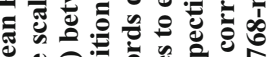

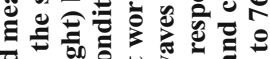

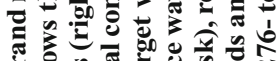
50 呵

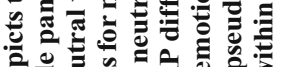

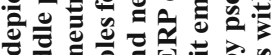

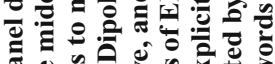

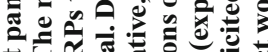
th

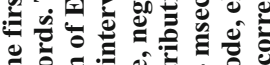

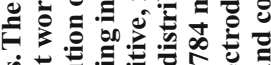

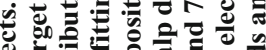
过

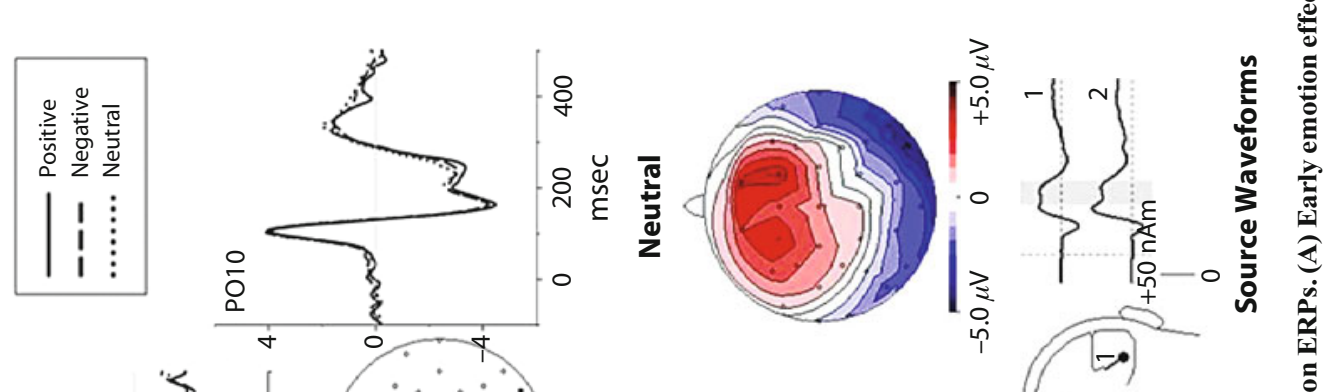

西

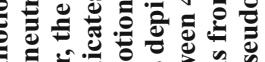

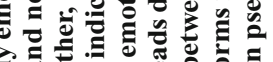

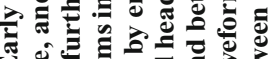
舟 ड

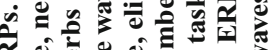

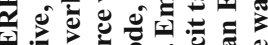

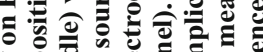

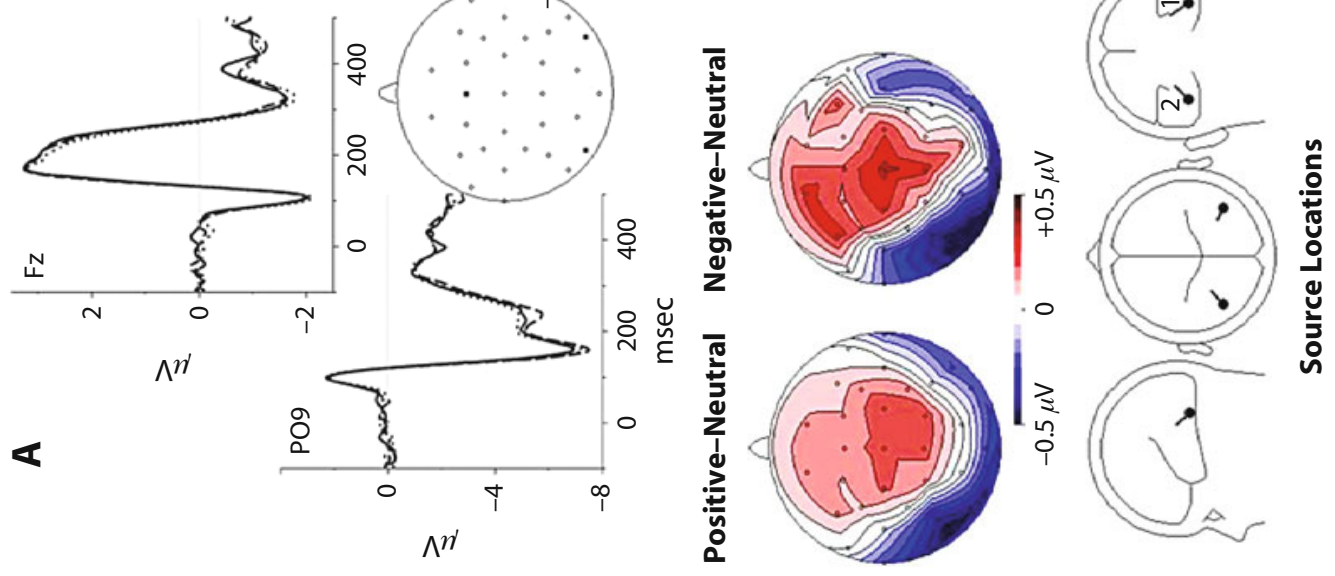

?

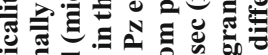
政 을

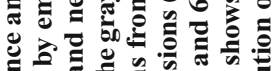

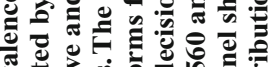

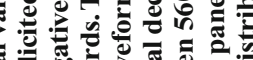

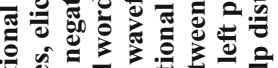

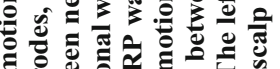

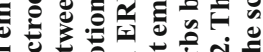

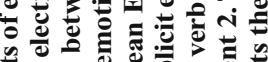

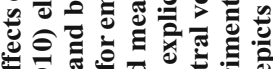

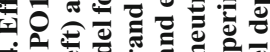
+2 过

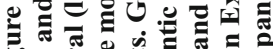

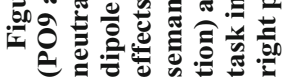


ment $[F(62,1426)=1.9, p<.05, \varepsilon=.179]$. This emotion effect consisted of significant differences between neutral verbs and both positive $[F(31,713)=2.5, p<.05, \varepsilon=$ $.216]$ and negative $[F(31,713)=2.3, p<.05, \varepsilon=.252]$ verbs. As compared with the earlier valence effect, this late effect showed markedly different scalp topography with parietal rather than frontal positivity and with frontotemporal rather than occipito-temporal negativity (see Figure 4B). Regional analysis on the Pz electrode revealed a significant main effect of emotion $[F(2,46)=6.0, p<$ $.01]$, consisting of enhanced amplitudes to both positive $[F(1,23)=16.0, p<.01]$ and negative $[F(1,23)=4.0, p<$ $.05]$ verbs, as compared with neutral target verbs. Furthermore, this late effect of emotional valence was modulated by task $[F(124,2852)=2.0, p<.05, \varepsilon=.134]$. As can be seen in Figure 4B, this effect was restricted to the semantic task $[F(62,1426)=2.2, p<.05, \varepsilon=.155]$ and the LDT $[F(62,1426)=2.3, p<.05, \varepsilon=.201]$ but was absent when structural decisions were performed $[F(62,1426)<$ 1.2]. Pairwise comparisons within the semantic task and LDT revealed significant differences between positive and neutral verbs $[F \mathrm{~s}(31,713)>2.6, p \mathrm{~s}<.05, \varepsilon \mathrm{s}=.197$ and .235 , respectively] and between negative and neutral verbs $[F(31,713)>2.7, p<.05, \varepsilon=.197]$.

Within the last time segment (672-956 msec), neither an effect of emotional valence nor an interaction between emotional valence and task appeared $\left(F_{\mathrm{s}}<1.3\right)$.

Figure 4B (right bottom panel) shows the ERPs from the explicit emotion rating task. In contrast to the three other tasks, in which the specific emotional valence of the target verbs was not task relevant, there was no early emotion effect. Emotion effects in the rating task appeared only within the LPC latency range between 432 and $784 \mathrm{msec}[F(62,1426)=2.8, p<.01, \varepsilon=.184]$ and, further, between 784 and $1,000 \mathrm{msec}[F(62,1426)=4.5$, $p<.001, \varepsilon=.164]$ after stimulus onset. Pairwise comparisons revealed significant differences between pairs with neutral and both positive and negative target verbs $[F \mathrm{~s}(31,713)>2.8, p \mathrm{~s}<.05, .155<\varepsilon \mathrm{s}<.252]$. Within both time segments, regional analyses at the Pz electrode confirmed the main effects of emotion $[F \mathrm{~s}(2,46)>7.2$, $p \mathrm{~s}<.01]$ and obtained significantly enhanced amplitudes to both positive $[F \mathrm{~s}(1,23)>5.3, p \mathrm{~s}<.01]$ and negative $[F \mathrm{~s}(1,23)>7.6, p \mathrm{~s}<.01]$ target verbs, as compared with neutral ones.

Effects of lexicality in ERPs. The lexicality effect was analyzed as the difference between pseudowords and correct target verbs (averaged over all emotion conditions) restricted to the LDT. As can be seen in Figure 4C, an enhanced negativity over the vertex was found between 276 and $768 \mathrm{msec}[F(31,713)=2.8, p<.05, \varepsilon=.133]$.

Within all time segments after $180 \mathrm{msec}$, significant main effects of task complexity appeared $\left[F_{\mathrm{s}}(62,1426)>\right.$ $1.9, p \mathrm{~s}<.05, .118<\varepsilon \mathrm{s}<.163]$. For brevity's sake, here, only effects of task complexity will be reported within the time segments of emotion effects. ANOVAs were conducted on mean amplitudes of ERP to the three different tasks, averaged across all conditions of emotion. Between 180 and $292 \mathrm{msec}$, an ANOVA revealed a significant ef- fect of task complexity $[F(62,1426)=1.9, p<.05, \varepsilon=$ .143], whereas none of the pairwise comparisons reached significance $\left[F_{\mathrm{s}}(31,713)<2.4, p \mathrm{~s}>.05, .155<\varepsilon \mathrm{s}<\right.$ .188]. Within the time segment of significant LPC modulations (560-672 msec), an ANOVA confirmed the significant task effect, as already found in the overall ANOVA $[F(62,1426)=4.1, p<.001, \varepsilon=.163]$, which refers to generally reduced ERP amplitudes to all verbs in semantic processing, as compared with structural $[F(31,713)=5.7$, $p<.001, \varepsilon=.199]$ and lexical $[F(31,713)=4.9, p<$ $.001, \varepsilon=.184]$ processing.

\section{Discussion}

The aim of Experiment 2 was to extend the findings of Experiment 1 about the effects of emotional valence from single verbs to verbs embedded in a meaningful context and, further, to assess the impact of the processing level by using different tasks. Replicating the results of Experiment 1, RTs were shorter and error rates were lower for positive than for neutral target verbs. In contrast to the single-verb condition, responses to negative target verbs following nouns were numerically, but not significantly, faster than those to neutral verbs. Furthermore, both the speed advantage for positive targets and-independently of emotional valence - overall, error rates increased from structural over lexical to semantic decisions, underlining the differences in the complexity of these tasks. ${ }^{5}$ This conforms to the idea that structural decisions operate at a shallower level of processing than do lexical decisions and these, in turn, are shallower than semantic decisions (Posner, 1969). Importantly, level of processing modulated the emotional effect, which became more pronounced as processing deepened.

In contrast to Experiment 1, ERPs showed two distinguishable emotion effects during the word comprehension process: an early effect starting around $200 \mathrm{msec}$ and a modulation of the LPC amplitudes starting $550 \mathrm{msec}$ after target verb presentation. The early emotion effect held similarly for both positive and negative valences and was characterized by an enhanced posterior negativity, which is typical for the EPN (e.g., Schupp et al., 2003). Interestingly, this early effect was independent of the processing level - that is, whether the tasks required structural, lexical, or semantic processing of the words. Although only the semantic decision task required the processing of the word's meaning, emotional aspects of the words seem to have been activated and processed, at least to some degree, also in the other-nonsemantic - tasks, resulting in the task-independent emotion effects in ERPs. Importantly, in all three conditions discussed so far, the word's emotional content was task irrelevant.

The second ERP effect of emotional valence is temporally and qualitatively distinguishable from the early one. It started around $550 \mathrm{msec}$ after target onset and was maximal over parietal scalp areas, similar to what has been reported many times before as an effect on the LPC (Naumann et al., 1997; Schupp et al., 2000). Here, this effect was clearly present only in the lexical, the semantic, and the explicit emotional judgment tasks. Although in 
the latter condition the stimuli were presented for a second time within the experimental session and response requirements were different, it yielded an LPC effect of emotion with a similar topography, as in the other conditions. This finding mostly replicates task-modulated LPC effects as reported by Naumann et al. (1997) and Fischler and Bradley (2006). However, it has to be noted that in the latter study, LPC amplitudes to emotional words during lexical decisions were only slightly enhanced, which could have resulted from specific task demands since overt responses were required only to pseudowords. Summarizing the main points, our finding provides more evidence that LPC modulations by emotional valence require explicit attention to the meaning of a word or, at least, a lexico-semantic processing level.

It is noteworthy that during the time period immediately preceding the LPC onset, there was a negative deflection in the ERPs to both negative and neutral words (cf. Figure 4B) that showed a local maximum around $400 \mathrm{msec}$, which is typical for the N400 component (e.g., Kutas \& Van Petten, 1994). Although the participants were instructed to read both the noun and verb, irrespective of the given task, only the semantic decision task explicitly required the processing of both sequentially presented words for successful task performance. Possibly, positive verbs are more typical or more often expected followers of the preceding emotionally neutral nouns, thus eliciting a smaller N400 component than did negative or neutral verbs. Furthermore, when both terms of the word pair were presented simultaneously in the emotional rating task, a slight negative deflection for negative and neutral targets preceded the emotional LPCs. Therefore, it is possible that the semantic integration of positive situations or actions (verbs) into a neutral context (nouns) is facilitated, as compared with negative or neutral information, by this type of lexical/semantic priming. Both preexperimental ratings of association strength and behavioral data support this idea. Although not significantly, positive verbs were judged as somewhat more related to the neutral nouns $(M=3.5)$ than were negative and neutral verbs $(M=3.1)$; in addition, positive verbs were processed more quickly and more accurately in all the tasks. However, these differences in relatedness obviously do not impact the emotion effects, because they are present to a similar degree for both positive and negative words, as compared with neutral ones.

\section{GENERAL DISCUSSION}

The present study addressed two major issues. The first aim was to localize the effects of emotional valence within the stream of visual word processing and, particularly, to track the onset and time course of these effects. Second, we investigated these emotion effects at different taskdetermined levels of word processing.

In Experiment 1, an LDT on single verbs that were emotionally positive, negative, or neutral was performed. The results showed an effect of emotional valence on performance because lexical decisions on both positive and negative verbs were faster than those on neutral verbs. In ERPs, an effect of emotion was found about $370 \mathrm{msec}$ after stimulus onset, consisting of an enhanced negativity on posterior electrode sites and - as its counterparta frontocentral positivity to both positive and negative, as compared with neutral, verbs. A lexicality effect in ERPs was found $50 \mathrm{msec}$ prior to the onset of the emotion effect.

In Experiment 2, emotional verbs were embedded in a semantic context provided by preceding nonemotional nouns. In addition to lexical decisions, two further tasks were performed with structural and semantic decisions, taken to be shallower and deeper than lexical decisions, respectively. As task level deepened, performance data showed an increasing advantage in both speed and accuracy for emotionally positive verbs. Interestingly, the speed advantage for negative target verbs, such as that found in Experiment 1, vanished when the verbs were embedded in context information. As was mentioned above, these differences might be due to an enhanced difficulty of semantic integration for negative, as compared with positive, verbs.

\section{Early Effects of Emotional Valence Are Task Independent}

A major finding of the present experiments is an early emotion effect in ERPs characterized by a pronounced occipito-temporal negativity to both positive and negative words, as compared with neutral ones. This scalp distribution is typical for the EPN (e.g., Schupp et al., 2003), which is reliably found in emotional picture processing and was suggested to reflect enhanced perception of emotional stimuli. Increased activation by emotional, as compared with neutral, stimuli was observed in visual areas such as the occipital and fusiform gyri (Davis \& Whalen, 2001; Pessoa et al., 2002). In line with these findings, Schupp et al. (2003; Schupp et al., 2007) suggested that more attention is allocated to emotional pictures in a reflex-type way, which enhances EPN amplitudes. Attention to distinct stimulus features is associated with a broadly distributed negative ERP defection over temporo-occipital regions occurring $\sim 150-350 \mathrm{msec}$ after stimulus onset. This occipital negativity effect reflects a transitory processing period at which task-relevant stimuli are presumably selected for elaborate processing (cf. Potts \& Tucker, 2001). It was therefore suggested that emotional stimuli spontaneously catch attention (e.g., Kissler et al., 2007; Schupp et al., 2007). Hence, Vuilleumier and Driver (2007) proposed that both attentional and emotional effects on visual perception are due to top-down influences upon the visual cortex from brain regions further upstream. Although the upstream networks may differ, their effects upon processing in the peristriate cortex may consist of similar activation patterns. As has recently been proposed by Kissler et al. (2007), bidirectional connections between the limbic structures and extrastriate regions might amplify the ERP responses to emotional words. Acknowledging the limitations in spatial resolution of dipole source analysis, our dipole model is consistent with the suggestion that the 
neural sources for ERPs to neutral and emotional verbs around the latency of the early emotional effect are located in such inferotemporal brain structures (see Schupp et al., 2007), which are part of the ventral visual processing stream (Ungerleider \& Mishkin, 1982).

Supporting evidence for the automaticity of emotional processing (at initial stages) comes from the task independency of the early emotion effect obtained in the present study. The structural decision task used in Experiment 2 required only a shallow processing of the given letter strings for successful performance but, nevertheless, yielded an early emotion effect. Interestingly, previous studies with comparably superficial tasks had failed to show any ERP differences according to semantic word properties (e.g., Chwilla et al., 1995; West \& Holcomb, 2000). However, if processing in the structural decision task were confined to detecting visual feature variations, an ERP effect of the emotional valence of the verbs should not appear, since it is highly implausible that emotional aspects are represented in specific visual (morphological) word features. Therefore, the present findings suggest also that more linguistic information had been extracted in this task, even though such information was irrelevant for successful performance. In contrast, lexical decisions require more than surface information. For successfully discriminating a word from pseudowords, lexical information, at least, has to be activated. Since several studies have shown semanticpriming effects also in LDTs (e.g., Fischler, 1977; Holcomb, 1988), it is suggested that the core meaning of a word may be automatically activated during this task. Further clues have come from studies in which different lexico-semantically related ERP modulations have been observed at early processing stages in LDTs (e.g., Hauk, Davis, et al., 2006; Hauk, Patterson, et al., 2006). The present data support this view.

Interestingly, the early emotion effect in Experiment 2 started about $200 \mathrm{msec}$ earlier than in Experiment 1. This dissociation in the time course of the effects cannot be explained by different properties of the target verbs used, since a large number of target verbs were identical in both experiments and, on average, the verbs were comparable with respect to structural and lexico-semantic control variables. Furthermore, emotional effects arising from the preceding nouns can be ruled out, since each of the nouns was presented as a prime for verbs of all valences in Experiment 2. Therefore, we suggest that the accelerated emotion effects in Experiment 2 can be explained by the involvement of a top-down mechanism triggered by the preceding context provided by the nouns, which preactivate possible candidates for meaningful verb candidates (Collins \& Loftus, 1975; Neely, 1991; Posner \& Snyder, 1975). Due to this preactivation, the access to the lexicon and the meaning of the verbs would be accelerated.

Such an accelerated access to lexical information by semantic priming might also explain the boost of the lexicality effect in Experiment 2, which appeared to be facilitated by around $50 \mathrm{msec}$. However, please note that the segments in which the lexicality effects emerged were very wide. Semantic-priming effects have been shown in a variety of psycholinguistic tasks, such as lexical decisions (e.g., Fischler, 1977; Holcomb, 1988; Meyer \& Schvaneveldt, 1971), naming (e.g., Balota \& Lorch, 1986), and item recognition (e.g., Ratcliff \& McKoon, 1978), and also in shallow processing tasks (e.g., Smith, Theodor, \& Franklin, 1983). According to some models, spreading activation has all the characteristics of an automatic process because it is fast, is of short duration, does not require attention or awareness, and places no or only minimal demands on resource capacity (Collins \& Loftus, 1975; Posner \& Snyder, 1975; Shiffrin \& Schneider, 1977).

\section{Late Effects of Emotional Valence Are Task Dependent}

The second major finding of the present study is the relationship between emotional valence and the amplitude of the LPC, confirming many previous reports that have shown that the amplitude of the LPC is enhanced by the emotional content of pictures, faces, or words (e.g., Cuthbert et al., 2000; Fischler \& Bradley, 2006; Schupp et al., 2000). Importantly, in contrast to the early emotion effect discussed above, the emotion effect on LPC amplitude was highly task dependent. In Experiment 2, clear effects of emotional valence were obtained in the lexical and semantic tasks and during explicit emotion rating. In contrast, no effects of emotional valence on LPC amplitude were found in the shallow structural task. If the LPC reflects an elaborative processing of emotional stimuli caused by their intrinsic relevance, this continued processing might appear only when lexico-semantic aspects are activated by specific task demands. This is not the case in shallow structural tasks and is the case only to a very small degree, at best, during lexical decisions.

\section{Summary and Conclusion}

The present findings are consistent with the following notion about emotion processing in word recognition. The emotional valence of words affects at least two processes reflected in the two main ERP components investigated here. First, there is a relatively early effect of emotion, reflected in the EPN, which is independent of the task or processing level. Because of its similarity to early ERP effects to emotional pictures, one might suggest that the present EPN effects for words also are the consequence of a reflex-like allocation of attention to emotional words. Nevertheless, the elicitation of this attention effect may be based on a fast analysis of the words' meaning - that is, on the access to the verb concept. This access appears to be automatic and independent of the task at hand, consistent with many suggestions of word processing (Kahneman \& Chajczyk, 1983; Stroop, 1935). The strong acceleration of this early emotion process when a semantic context is provided by a prime word may be explained with a valence-unspecific activation of possible conceptual verb candidates. This sort of semantic priming may explain why the emotion effects in the EPN are essentially un- 
altered in amplitude but become considerably shorter in latency. That there is also some, albeit much smaller, acceleration of the lexicality effect may be explained by a preactivation of verb candidates in the visual lexicon, an effect that may contribute, to some extent, to the semantic priming effect. A second, later effect of emotional word content is reflected in the LPC. This later emotion effect depends in its amplitude on the task relevance of word meaning's boosting the intrinsic salience of valent words. One may suggest that the emotional verbs that have received more attentional resources on the processing stage reflected in the EPN are now submitted to more elaborate processing. This elaborate processing, however, depends on the task at hand and is more pronounced in LDTs and, especially so, in semantic tasks.

\section{AUTHOR NOTE}

This work was supported by the German Research Foundation (DFG, GRK 423). We thank Rainer Kniesche and Thomas Pinkpank for technical support and Rasha Abdel Rahman for inspiring discussions. Correspondence concerning this article should be addressed to A. Schacht, Department of Psychology, Humboldt University at Berlin, Unter den Linden 6, D-10099 Berlin, Germany (e-mail: schachta@hu-berlin.de).

\section{REFERENCES}

Baayen, R. H., Piepenbrock, R., \& van Rijn, R. (1995). The CELEX lexical database [CD-ROM]. Philadelphia: University of Pennsylvania, Linguistic Data Consortium.

Balota, D. A., \& Lorch, R. (1986). Depth of automatic spreading activation: Mediated priming effects in pronunciation but not in lexical decision. Journal of Experimental Psychology: Learning, Memory, \& Cognition, 8, 493-512.

Bashore, T. R., \& van der Molen, M. W. (1991). Discovery of the P300: A tribute. Biological Psychology, 32, 155-171.

Brandeis, D., Naylor, H., Halliday, R., Callaway, E., \& Yano, L. (1992). Scopolamine effects on visual information processing, attention, and event-related potential map latencies. Psychophysiology, 29, 315-336.

Braun, M., Jacobs, A. M., Hahne, A., Ricker, B., Hofmann, M., \& HutzLER, F. (2006). Model-generated lexical activity predicts graded ERP amplitudes in lexical decision. Brain Research, 1073-1074, 431439.

Cahill, L., Haier, R. J., Fallon, J., Alkire, M. T., Tang, C., Keator, D., ET AL. (1998). Amygdala activity at encoding correlates with long-term, free recall of emotional information. Proceedings of the National Academy of Sciences, 93, 8016-8021.

Chwilla, D. J., Brown, C. M., \& Hagoort, P. (1995). The N400 as a function of the level of processing. Psychophysiology, 32, 274-285.

Collins, A. M., \& LofTus, E. F. (1975). A spreading activation theory of semantic processing. Psychological Review, 82, 407-428.

Cuthbert, B. N., Schupp, H. T., Bradley, M., Birbaumer, N., \& LANG, P. J. (2000). Brain potentials in affective picture processing: Covariation with autonomic arousal and affective report. Biological Psychology, 52, 95-111.

DAHL, M. (2001). Asymmetries in the processing of emotionally valenced words. Scandinavian Journal of Psychology, 42, 97-104.

Davis, M., \& Whalen, P. J. (2001). The amygdala: Vigilance and emotion. Molecular Psychiatry, 6, 13-34.

Dehaene, S. (1995). Electrophysiological evidence for categoryspecific word processing in the normal human brain. NeuroReport, 6, 2153-2157.

Diedrich, O., Naumann, E., Maier, S., Becker, G., \& Bartussek, D. (1997). A frontal positive slow wave in the ERP associated with emotional slides. Journal of Psychophysiology, 11, 71-84.

Dietrich, D., Waller, C., Johannes, S., Wieringa, B. M., Emrich, H. M., \& MüNTE, T. F. (2001). Differential effects of emotional content on event-related potentials in word recognition memory. Neuropsychobiology, 43, 96-101.
Dijksterhuis, A., \& Aarts, H. (2003). On wildebeests and humans: The preferential detection of negative stimuli. Psychological Science, 14, 14-18

Federmeier, K. D., Segal, J. B., Lombrozo, T., \& Kutas, M. (2000). Brain responses to nouns, verbs and class-ambiguous words in context. Brain, 123, 2552-2566.

FISCHLER, I. (1977). Associative facilitation without expectancy in a lexical decision task. Journal of Experimental Psychology: Human Perception \& Performance, 3, 18-26.

Fischler, I., \& Bradley, M. (2006). Event-related potential studies of language and emotion: Words, phrases, and task effects. Progress in Brain Research, 156, 185-203.

Gratton, G., Coles, M. G. H., \& Donchin, E. (1983). A new method for off-line removal of ocular artifact. Electroencephalography \& Clinical Neurophysiology, 55, 468-484.

Hamann, S. B., Ely, T. D., Grafton, S. T., \& Kilts, C. D. (1999). Amygdala activity related to enhanced memory for pleasant and aversive stimuli. Nature Neuroscience, 2, 289-293.

Hauk, O., Davis, M. H., Ford, M., Pulvermüller, F., \& MarslenWILSON, W. D. (2006). The time course of visual word recognition as revealed by linear regression analysis of ERP data. NeuroImage, $\mathbf{3 0}$, 1383-1400.

Hauk, O., Patterson, K., Woollams, A., Watling, L., PulvermülLER, F., \& Rogers, T. T. (2006). [Q:] When would you prefer a SOSSAGE to a SAUSAGE? [A:] At about $100 \mathrm{msec}$. ERP correlates of orthographic typicality and lexicality in written word recognition. Journal of Cognitive Neuroscience, 18, 818-832.

Hauk, O., \& Pulvermüller, F. (2004). Effects of word length and frequency on the human event-related potential. Clinical Neurophysiology, 115, 1090-1103.

Herbert, C., Junghöfer, M., \& Kissler, J. (2008). Event related potentials to emotional adjectives during reading. Psychophysiology, 45, 487-498.

Herbert, C., Kissler, J., Junghöfer, M., Peyk, P., \& Rockstroh, B. (2006). Processing of emotional adjectives: Evidence from startle EMG and ERPs. Psychophysiology, 43, 197-206.

HoLcomв, P. J. (1988). Automatic and attentional processing: An eventrelated brain potential analysis of semantic priming. Brain \& Language, 35, 65-85.

Holcomb, P. J., \& Grainger, J. (2006). On the time course of visual word recognition: An event-related potential investigation using masked repetition priming. Journal of Cognitive Neuroscience, 18, 1631-1643.

Holcomb, P. J., \& Grainger, J. (2007). Exploring the temporal dynamics of visual word recognition in the masked repetition priming paradigm using event-related potentials. Brain Research, 1180, 39-58.

Hutzler, F., Bergmann, J., Conrad, M., Kronbichler, M., StenNECKEN, P., \& JACOBS, A. M. (2004). Inhibitory effects of first syllable-frequency in lexical decision: An event-related potential study. Neuroscience Letters, 372, 179-184.

Johnson, R., JR. (1988). The amplitude of the P300 component of the event-related potential. In P. K. Ackles, J. R. Jennings, \& M. G. H. Coles (Eds.), Advances in psychophysiology (Vol. 2, pp. 69-138). Greenwich, CT: JAI Press.

JunghöFer, M., Bradley, M. M., Elbert, T. R., \& LANG, P. J. (2001). Fleeting images: A new look at early emotion discrimination. Psychophysiology, 38, 175-178.

Kahneman, D., \& ChaJczyK, D. (1983). Tests of the automaticity of reading: Dilution of color-irrelevant stimuli. Journal of Experimental Psychology: Human Perception \& Performance, 9, 497-509.

Kauschke, C., \& Stenneken, P. (2008). Differences in noun and verb processing in lexical decision cannot be attributed to word form and morphological complexity alone. Journal of Psycholinguistic Research, 37, 443-452. doi:10.1007/s10936-008-9073-3

Kayser, J., Tenke, C., Nordby, H., Hammerborg, D., Hugdahl, K., \& Erdmann, G. (1997). Event-related potential (ERP) asymmetries to emotional stimuli in a visual half-field paradigm. Psychophysiology, 34, 414-426.

KeIL, A., \& IHSSEN, N. (2004). Identification facilitation for emotionally arousing verbs during the attentional blink. Emotion, 1, 23-35.

KeIL, A., Inssen, N., \& HeIM, S. (2006). Early cortical facilitation for emotionally arousing targets during the attentional blink. BMC Biology, 4, 23. doi:10.1186/1741-7007-4-23

Kissler, J., Assadolahi, R., \& Herbert, C. K. (2006). Emotional and 
semantic networks in visual word processing: Insights from ERP studies. Progress in Brain Research, 156, 147-183.

Kissler, J., Herbert, C., Peyk, P., \& Junghöfer, M. (2007). Buzzwords: Early cortical responses to emotional words during reading. Psychological Science, 18, 475-482.

Kissler, J., Herbert, C., Winkler, I., \& JunghöFer, M. (2009). Emotion and attention in visual word processing: An ERP study. Biological Psychology, 80, 75-83.

Kounios, J., \& Holcomb, P. J. (1994). Concreteness effects in semantic processing: ERP evidence supports dual-coding theory. Journal of Experimental Psychology: Learning, Memory, \& Cognition, 20, 804-823.

Kutas, M., \& Federmeier, K. D. (2000). Electrophysiology reveals semantic memory use in language comprehension. Trends in Cognitive Sciences, 4, 463-470.

Kutas, M., \& Van Petten, C. (1994). Psycholinguistics electrified: Event-related brain potential investigations. In M. A. Gernsbacher (Ed.), Handbook of psycholinguistics (pp. 83-143). San Diego: Academic Press.

Lang, P. J., Bradley, M. M., \& Cuthbert, B. N. (1997). Motivated attention: Affect, activation, and action. In P. J. Lang, R. F. Simons, \& M. Balaban (Eds.), Attention and orientation: Sensory and motivational processes (pp. 97-135). Mahwah, NJ: Erlbaum.

LANG, P. J., \& CUTHBert, B. N. (1984). Affective information processing and the assessment of anxiety. Journal of Behavioral Assessment, 6, 369-395.

Lehmann, D., \& Skrandies, W. (1980). Reference-free identification of components of checkerboard-evoked multichannel potential fields. Electroencephalography \& Clinical Neurophysiology, 48, 609-621.

Marslen-Wilson, W. D., \& TYler, L. K. (1980). The temporal structure of spoken language understanding. Cognition, 8, 1-71.

McClelland, J. L., \& Rumelhart, D. E. (1981). An interactive activation model of context effects in letter perception: Part 1. An account of basic findings. Psychological Review, 88, 375-407.

Meyer, D. E., \& SchVAnEveldT, R. W. (1971). Facilitation in recognizing pairs of words: Evidence of a dependence between retrieval operations. Journal of Experimental Psychology, 90, 227-234.

MurPhy, G. L. (1990). Noun phrase interpretation and conceptual combination. Journal of Memory \& Language, 29, 259-288.

Naumann, E., Bartussek, D., Diedrich, O., \& Laufer, M. E. (1992). Assessing cognitive and affective information processing functions of the brain by means of the late positive complex of the event-related potential. Journal of Psychophysiology, 6, 285-298.

Naumann, E., Maier, S., Diedrich, O., Becker, G., \& Bartussek, D. (1997). Structural, semantic, and emotion-focussed processing of neutral and negative nouns: Event-related potential correlates. Journal of Psychophysiology, 11, 158-172.

NeELY, J. H. (1991). Semantic priming effects in visual word recognition: A selective review of current findings and theories. In D. Besner \& G. W. Humphreys (Eds.), Basic progress in reading: Visual word recognition (pp. 244-333). Hillsdale, NJ: Erlbaum.

Nelson, K. (1973). Structure and strategy in learning to talk. Chicago: University of Chicago Press.

OLDFIELD, R. C. (1971). The assessment and analysis of handedness: The Edinburgh inventory. Neuropsychology, 9, 97-113.

Pecher, D., Zeelenberg, R., \& Wagenmakers, E. J. (2005). Enemies and friends in the neighborhood: Orthographic similarity effects in semantic categorization. Journal of Experimental Psychology: Learning, Memory, \& Cognition, 31, 121-128.

Pessoa, L., Kastner, S., \& Ungerleider, L. G. (2002). Attentional control of the processing of neutral and emotional stimuli. Cognitive Brain Research, 15, 31-45.

Picton, T. W., \& Hillyard, S. A. (1988). Endogenous event-related potentials. In T. W. Picton (Ed.), Human event-related potentials: EEG handbook (Rev. series, Vol. 3, pp. 361-426). Amsterdam: Elsevier.

Polich, J. (2007). Updating p300: An integrative theory of P3a and P3b. Clinical Neurophysiology, 118, 2128-2148.

PosNer, M. I. (1969). Abstraction and the process of recognition. In G. H. Bower (Ed.), Advances in learning: The psychology of learning and motivation (pp. 43-100). New York: Academic Press.

Posner, M. I., \& SNYDER, C. R. R. (1975). Attention and cognitive control. In R. L. Solso (Ed.), Information processing and cognition: The Loyota Symposium (pp. 55-85). Hillsdale, NJ: Erlbaum.
Potts, G. F., \& Tucker, D. M. (2001). Frontal evaluation and posterior representation in target detection. Cognitive Brain Research, 11, 147-156.

Pratto, F., \& John, O. P. (1991). Automatic vigilance: The attentiongrabbing power of negative social information. Journal of Personality \& Social Psychology, 61, 380-391.

Pulvermüller, F., Assadollahi, R., \& Elbert, T. (2001). Neuromagnetic evidence for early semantic access in word recognition. European Journal of Neuroscience, 13, 201-205.

Pulvermüller, F., Härle, M., \& Hummel, F. (2001). Walking or talking? Behavioral and neurophysiological correlates of action verb processing. Brain \& Language, 78, 143-168.

Rastle, K. (2007). Visual word recognition. In M. G. Gaskell (Ed.), The Oxford handbook of psycholinguistics (pp. 71-88). Oxford: Oxford University Press.

Ratcliff, R., \& McKoon, G. (1978). Priming in item recognition: Evidence for the propositional structure of sentences. Journal of Verbal Learning \& Verbal Behavior, 17, 403-417.

Reynolds, A. G., \& FlaGg, P. W. (1976). Recognition memory for elements of sentences. Memory \& Cognition, 4, 422-432.

SCHERG, M., \& BERG, P. (2000). BESA Version 5.0.4 [Computer software]. Munich: Megis.

Schupp, H. T., Cuthbert, B. N., Bradley, M. M., Cacioppo, J. T., ITo, T., \& LANG, P. J. (2000). Affective picture processing: The late positive potential is modulated by motivational relevance. Psychophysiology, 37, 257-261.

Schupp, H. T., Hamm, A. O., \& WeIKe, A. I. (2003). Emotional facilitation of sensory processing in the visual cortex. Psychological Science, 14, 7-13.

Schupp, H. T., JunghöFer, M., Weike, A. I., \& Hamm, A. O. (2004). The selective processing of briefly presented affective pictures: An ERP analysis. Psychophysiology, 41, 441-449.

Schupp, H. T., Stockburger, J., Codispoti, M., Junghöfer, M., Weike, A. I., \& Hamm, A. O. (2007). Selective visual attention to emotion. Journal of Neuroscience, 27, 1082-1089.

SCHWANENFLUGel, P. (1991). Why are abstract concepts hard to understand? In P. Schwanenflugel (Ed.), The psychology of word meanings (pp. 223-250). Hillsdale, NJ: Erlbaum.

Scott, G. G., O’Donnell, P. J., Leuthold, H., \& Sereno, S. C. (2009). Early emotion word processing: Evidence from event-related potentials. Biological Psychology, 80, 95-104.

SeidenberG, M. S., \& MCClelland, J. L. (1989). A distributed, developmental model of word recognition and naming. Psychological Review, 96, 523-568.

Sereno, J. A. (1999). Hemispheric differences in grammatical class. Brain \& Language, 70, 13-28.

Sereno, S. C., Rayner, K., \& Posner, M. I. (1998). Establishing a time-line of word recognition: Evidence from eye movements and event-related potentials. NeuroReport, 9, 2195-2200.

Shiffrin, R. W., \& SchneIder, W. (1977). Controlled and automatic human information processing: II. Perceptual learning, automatic attending, and a general theory. Psychological Review, 84, 127-190.

Smith, M. C., Theodor, L., \& Franklin, P. E. (1983). The relationship between contextual facilitation and depth of processing. Journal of Experimental Psychology: Learning, Memory, \& Cognition, 9, 697-712.

Stroop, J. R. (1935). Studies of interference in serial verbal reactions. Journal of Experimental Psychology, 18, 643-662. (Reprinted 1992 in Journal of Experimental Psychology: General, 121, 15-23)

Talairach, J., \& Tournoux, P. (1988). Co-planar stereotaxic atlas of the human brain. New York: Thieme.

Tyler, L. K., Russel, R., Fadili, J., \& Moss, H. E. (2001). The neural representations of nouns and verbs: PET studies. Brain, 124, 16191634.

Ungerleider, L. G., \& Mishrin, M. (1982). Two cortical visual systems. In J. Ingle, M. A. Goodale, \& R. J. W. Mansfield (Eds.), Analysis of visual behavior (pp. 549-586). Cambridge, MA: MIT Press.

VuILleumier, P. (2005). How brains beware: Neural mechanisms of emotional attention. Trends in Cognitive Sciences, 9, 585-594.

Vuilleumier, P., \& Driver, J. (2007). Modulation of visual processing by attention and emotion: Windows on causal interactions between human brain regions. Philosophical Transactions of the Royal Society $B, \mathbf{3 6 2}, 837-855$. 
West, W. C., \& Ноцcomb, P. J. (2000). Event-related potentials during discourse-level semantic integration of complex pictures. Cognitive Brain Research, 13, 363-375.

White, M. (1996). Automatic appraisal of words. Cognition \& Emotion, 10, 199-211.

Ziegler, J. C., Besson, M., Jacobs, A. M., Nazir, T. A., \& Carr, T. H. (1997). Word, pseudoword, and nonword processing: A multitask comparison using event-related brain potentials. Journal of Cognitive Neuroscience, 9, 758-775.

\section{NOTES}

1. Perceived arousal values were obtained using a computerized version of the self-assessment manikin (SAM; Lang \& Cuthbert, 1984).

2. To make sure that the absence of any earlier emotion effects is not due to the particular type of ERP analysis, an additional regional analysis on the activity of five occipito-temporal electrodes (PO9,
PO10, O1, O2, and Iz) was conducted. This repeated measures ANOVA with factors of emotion (3) and electrode (5) did not show a significant main effect of emotion or an emotion $\times$ electrode interaction $\left(F_{\mathrm{S}}<1\right)$.

3. Rating values for emotional valence and imageability were obtained using 7-point rating scales. Emotional arousal has been rated using a computerized version of the SAM (Lang \& Cuthbert, 1984). Association strength was evaluated on a 5-step rating scale on which participants had to judge to which extent the action word (verb) is a typical follower of the noun.

4. Please, note that both verbs and nouns were unambiguous candidates of their word classes.

5. Longer RTs for structural than for lexical decisions might relate to task requirements. For structural decisions, the distractor words included one italicized letter, which might have been detected in an up out fashion. Therefore, RTs were shorter for distractor trials $(M=751.6)$ than for correct trials $(M=845.3)$.

\section{APPENDIX}

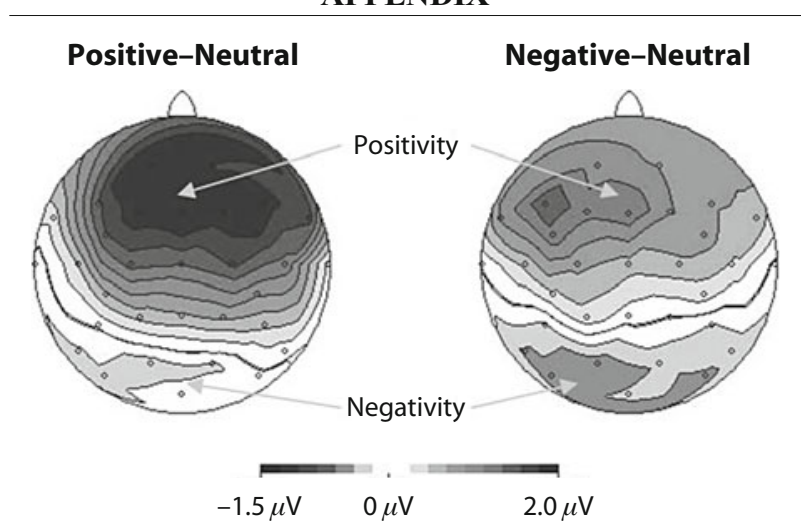

Figure A1. Distribution of the emotion effect between 368 and 488 msec obtained in Experiment 1, using an average-mastoid reference.

(Manuscript received January 11, 2008; revision accepted for publication September 6, 2008.) 